\title{
Dynamics and bases of recoveries of functions after injuries to the cerebral cortex
}

\author{
DONALD R. MEYER and PATRICIA M. MEYER \\ The Ohio State University, Columbus, Ohio 43212
}

\begin{abstract}
A review of the principal results of a 20-year program, at Ohio State University, of quantitative studies of the problem of recovery from damage to the brain.
\end{abstract}

This review considers the principal results of a program of quantitative studies of the problem of recovery from damage to the brain. The program was begun some 20 years ago as an effort to understand the curious results of a classical experiment of Lashley (1935). Lashley observed that if hooded rats are trained to choose the brighter of a pair of doors, they show no postoperative retention of the habit when retested after having been subjected to bilateral ablations of the posterior regions of the dorsolateral cortex. But he also observed that posterior preparations, if given further training on the task, relearn the black-white habit at a rate that is not very different from the rate at which the habit is initially acquired by normal subjects.

Lashley's observations thus suggested that retention of the habit could be readily suppressed by an ablation that is virtually without effect upon a rat's capacities for learning or relearning of the habit. Hence, the first question was why, if it is true that the habit can be learned just as quickly by braindamaged subjects as by normal animals, performance of the habit should be cortically dependent provided that the cortex is present. That is, the animals had obviously not been reduced to a condition where they lacked some essential system for performance of the habit, and yet they behaved as though the operations had deprived them of all recognition of the fact that they had ever seen the problem before.

The investigations described in this review were supported in part by National Institute of Mental Health Grants MH-02035 and MH-06211. P. M. Meyer is a United States Public Health Service Research Scientist and Investigator (5-Ko-MH-12,747) of the National Institute of Mental Health. From the Laboratory of Comparative and Physiological Psychology, Ohio State University: To our former students, whose thoughts, skills, and labor have contributed so much to the conception, design, and execution of the studies in the program, we express our deep appreciation and our fondest regards. We also wish to thank Ms. Elaine Wells Carlson for her assistance in the preparation of the manuscript. And, finally, we wish to note that David G. Lavond, who subjected the draft to an unusually constructive critique, enabled us to see some implications in the findings that had theretofore completely escaped us.
A second basic question was whether, in recovering from ablations of the posterior cortex, the subjects were relearning the habit with systems related to the still-intact anterior cortex. We found that there were two ways of looking at that possibility. One was to presume, as Pavlov (1927) had proposed, that recoveries of visual habits that are lost when the posterior cortex is destroyed is possible because the anterior cortex normally has visual as well as other kinds of functions. The other was to think that the anterior cortex normally has nonvisual functions, but acquires visual functions through plastic adaptations of the brain to a posterior injury.

There also were questions as to whether the impairments were functions of perceptual disorders, of losses of associative substrates for the habit, or of failures of memorial retrieval. The then-prevailing theory was that memories are stored as modifications of the cortex, and hence the most popular interpretation of the loss of retention of the black-white habit was that it was due to destruction of an engram that forms in the posterior cortex when normal animals are trained on the habit. Somewhat less attention was then being paid to a substitutive theory of recovery in which the presumption was that normal rats acquire the black-white habit as a visual pattern problem and then, when deprived of the use of pattern vision, postoperatively acquire a new and different habit of responding to differences in flux. The third possibility was seldom discussed, for the failures of retention were complete, and most investigators were inclined to believe that the impairments were too profound to be regarded as due to effects upon remembering.

As the program developed, we encountered other issues, and these will be described in due course. Our underlying motive for the work has been our interest in the problems of victims of strokes, and particularly strokes which involve the cerebral cortex and result in memorial disorders. We have studied recoveries of black-white habits because, from the outset, we believed that Lashley's findings suggested a model that could fruitfully be used to explore the assumptions of theories of therapy for strokes. 
Hence, we have not only sought the bases for his findings, but have also been concerned with the question of whether the reversible impairments he described are treatable with novel interventions.

\section{SUBJECTS, APPARATUS, AND GENERAL METHODS}

Approximately 1,500 Long-Evans male hooded rats have served as subjects for the studies. They were typically from 90 to 120 days of age when each experiment began. Males were employed in preference to females because of their greater tolerance of sodium pentobarbital, which was used as the principal anesthetic agent during most of the surgical procedures. The animals were housed in separate cages, and were maintained on an ad-lib food and water schedule.

The animals were trained in the Thompson-Bryant (1955) shockavoidance version of the Yerkes-Watson-Munn apparatus (Figure 1). In most of the experiments, the subjects were required to escape from the choice compartment of the apparatus by displacing an unlocked white door. The white door was paired with a locked black door, with the luminances of the white and black doors being approximately 3 and $.1 \mathrm{~mL}$, respectively. The positions of the doors on any given trial were governed by a Gellermann series (1933). Preoperative training was preceded by pretraining sessions during which the animals were trained to exit promptly

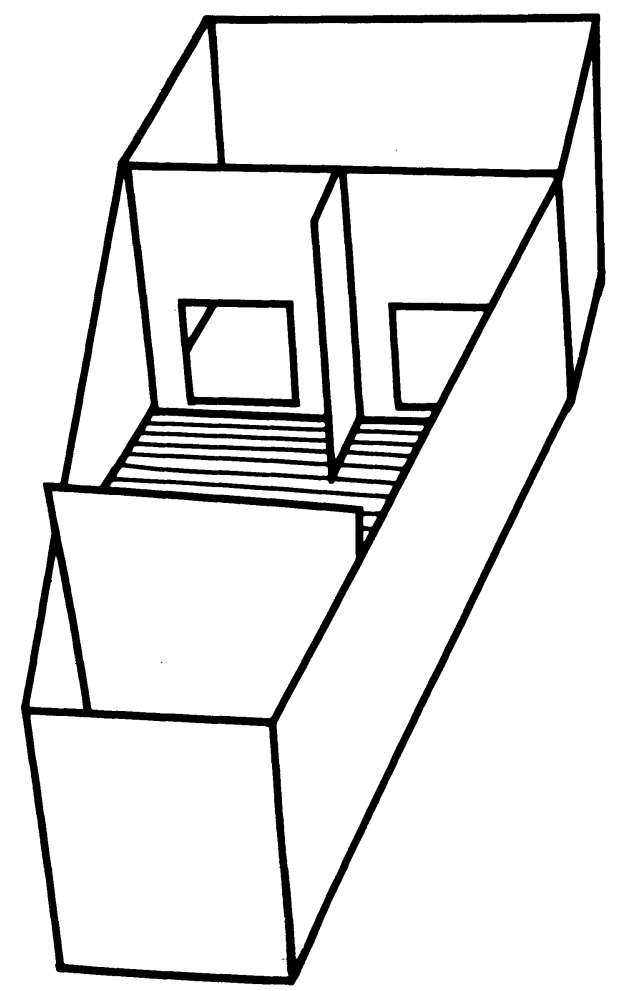

Figure 1. The Thompson-Bryant apparatus. The interior was illuminated with a group of small fluorescent lamps which were attached to a transparent plastic lid that covered the choice compartment. When the animal responded to the positive door, the door fell backward into the goal compartment, which the subject then entered by running across the stimulus. This arrangement was designed to minimize the S-R spatial contiguity effect, which many experiments have shown to be a potent determinant of the efficiency with which discriminations are acquired (cf. Meyer, Treichler, \& Meyer, 1965). from a startbox and then the choice compartment. When they failed to do so, they were given mild shocks to the feet through a grid that formed the floor of the apparatus. Pretraining was omitted when the animals were tested for postoperative retention of the habit, for the ancillary skills thus established were observed to be well retained after most of the surgical procedures.

In some of the experiments, the subjects were trained on a pattern discrimination problem. The training was conducted with doors which displayed arrays of black and white stripes. The stripes were at angles of $45^{\circ}$ to the left or right of vertical. The doors were constructed of the same materials as were used to make the all-white and all-black doors that were used for training subjects on the brightness problem. Two kinds of left-oblique and right-oblique panels were employed, and in one kind the black stripes were in the positions of the white stripes in the other kind. The stripes were approximately $2.5 \mathrm{~cm}$ wide per cycle.

For the first few years, the animals were trained with a massedtrial procedure that has been described by Horel, Bettinger, Royce, and Meyer (1966). The massed-trial procedure yielded mean learning scores for the black-white problem of approximately 50 trials to a criterion of $9 / 10$ correct responses. Thereafter, beginning with a study of Glendenning (1972), a spaced-trial procedure was adopted. The spaced-trial procedure served to reduce the mean preoperative scores to approximately 25 trials, and hence it was adopted after Glendenning showed that the change in the method was without effect upon the relative performances of normal and operated subjects.

Our students, after having learned to use these methods, have almost invariably suggested that the problem could be more conveniently approached through the use of automated training procedures. Our reply to them has been that we have tried other methods, and found that those methods were much less efficient than classical discrimination training. For example, in the very early stages of the program, we proposed to train rats to press a bar to avoid shock whenever a light was turned on. We found that normal animals would fail to learn the task after thousands of light-shock pairings (Meyer, Cho, \& Weseman, 1960). The findings, which were early post-Skinnerian indications of the nonarbitrariness of operants as factors in instrumental learning (cf. Bolles, 1970), have only very rarely been described by later workers in the field of constraints upon learning. We found them interesting, but we were much more interested in neuropsychological research. Hence we adopted the Thompson-Bryant method and continued to employ it when we found that the outcomes obtained with the method were stable.

In most of the experiments, the rats were subjected to ablations of the anterior and/or the posterior halves of the dorsolateral cortex. The surgical procedures are described in detail by Meyer and Meyer (1971). The lesions were produced by the aspiration method and/or the pia-stripping method, and the bregma was taken as the landmark for the medial point of demarcation between an anterior ablation and a posterior ablation. Accordingly, the limits of the posterior lesions extended far forward of the visual cortex as the zone had been defined by electrophysiological studies of Woolsey and his colleagues (cf. Woolsey, Settlage, Meyer, Sencer, Pinto-Hamuy, \& Travis, 1950). The posterior ablations typically produced complete degenerations of the dorsal divisions of the lateral geniculate bodies. The lateral geniculates were only very rarely affected by anterior ablations, which usually resulted in severe degenerations of the thalamic ventrobasal complex.

Our decision with respect to the scope of the posterior ablation has proved to be propitious. Thus we now know, from experiments of Hughes (1976), that all of the regions of the posterior cortex which are shaded in the chart in Figure 2 receive a visually significant projection from one or more of two thalamic sources. The lateral geniculates are one source, and the nucleus lateralis posterior is the other source. Hughes has shown that the geniculate projections terminate in area 17 of Krieg (1946) but also in at least some subdivisions of area $18 \mathrm{~A}$ of Krieg. The geniculate projections converge with projections from NLP in area $18 \mathrm{~A}$, and NLP also projects to areas 18, 7, 20, and possibly 17 of Krieg. 


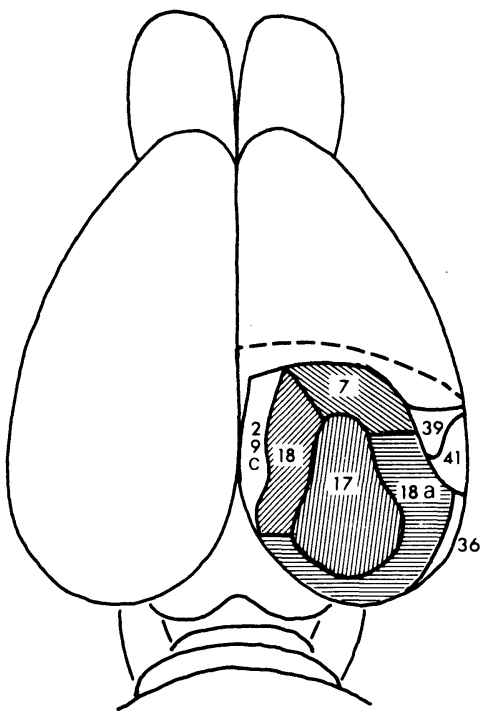

$A$

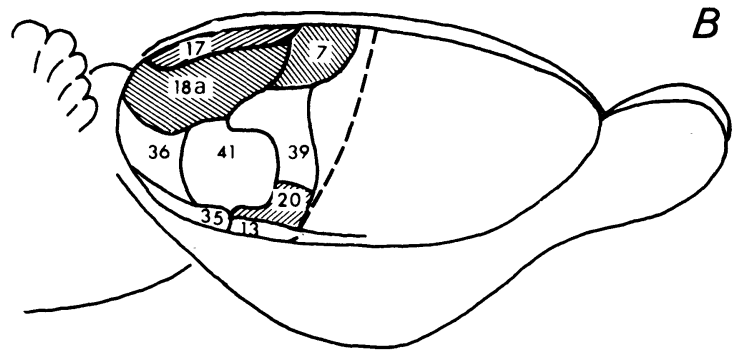

Figure 2. The lesions of intent, and the rat's visual cortex as defined by regions which receive projections from the dorsal lateral geniculate bodies, the nucleus lateralis posterior, or both. The subdivisions and the numbers of the field are from the cytoarchitectural map of Krieg (1946). The typical posterior lesion included all of fields with the possible exception of area 20 , and the typical anterior lesion did not encroach upon any of the fields.

Hence there are two posterior visual systems in the rat, and only a very large posterior ablation will destroy all their zones of termination in the posterior cortex.

In recent years, the scopes of our anterior ablations have been somewhat smaller than they were when we first began our studies. The reductions were made to avoid a complication that we first encountered in experiments described by Horel et al. (1966). Therein we observed that radical anterior ablations result in severe, but transitory, hypophagias. Other observations led us to suspect that the complication was related to destructions of the lateral margins of the region. Experiments of Braun (1975) and of Kolb and Nonneman (1976) have validated our suspicions, which led us to refrain from extending the anterior ablations to the rhinal fissures. This has been the only important variation in our cortical surgical procedures, and we have seen no suggestion that the variation has made any difference insofar as performances of blackwhite habits are concerned.

In some of the experiments, the rats were prepared with ablations of subcortical structures. The ablations were accomplished through the use of stereotaxic methods. Initially, regardless of the kind of operation, the subjects were permitted to recover from the surgery for a period of 21 days. However, beginning with the study of Glendenning (1972), the interval was shortened to 11 days except when the subjects were prepared with superior collicular ablations. In addition, one group of rats prepared with radical bilateral anterior ablations was given extra time to recover for assessments of the role of inanition in the deficits of blackwhite performances that anterior subjects exhibit.

In many of the studies, the effects of successive cerebral ablations were examined. Rats thus prepared were permitted to recover for either 21 or 11 days following each operation. When data are presented for serial preparations, the schematic brain diagrams within the figures depict the older lesions with cross-hatched lines and the second-stage lesions in black. With very rare exceptions, the findings for relearning after second-stage serial ablations were for subjects that had also been retrained on the habit following the first-stage ablations. Hence, three results are frequently compared: original learning of the habit $(\mathrm{OL})$, first or interoperative relearning or retention of the habit $\left(R_{1}\right)$, and second relearning or ultimate retention of the habit $\left(\mathbf{R}_{2}\right)$.

The findings are presented in terms of learning curves which give the mean trials that various preparations took to learn or relearn the black-white habit to a series of successively more stringent criteria of performance of the habit. The method of construction of the curves, which was first described by Melton (1936), was to average the trials that all the subjects in a group required to meet criteria of $1,2,3,4,5,6,7,8$, or 9 correct responses in 10 trials. The advantage of the method was that it permitted assessments of the average rates of learning for subjects that required different numbers of training trials to reach the terminal criterion of performance. When the scores were averaged, the criterial trials were first subtracted from each subject's total trials and hence, if the $9 / 10$ criterion was met in 10 trials, the animal's score was 0 trials.

Most of the studies have been relatively simple in design and, in general, we have worked with comparatively large groups of subjects. We base our conclusions upon differences or lack of differences between group means. The captions of the figures present the learning or relearning scores for the groups that are compared in the figures, and also give the standard errors of the scores for the groups. All of these values are for the trials required to reach the $9 / 10$ criterion.

Because many people participated in the collection of the data we present, a system of long-term quality control was necessary. The system operated as follows. First, the expected rate of learning of the habit was determined from the scores obtained from 68 normal animals. Thereafter, as further groups of animals were studied, the preoperative scores for the new groups were compared with preoperative scores of the initial group as a check against drifts in the training procedure and/or the characteristics of the subjects. Drifts in the surgical procedures were caught through inclusions of at least one replicative group of operated subjects in each of the successive studies. When discrepancies appeared, the problem was resolved with further replications by a third individual, who carried out the studies without communicating with either of his two predecessors.

A number of the latest studies in the program have not been separately described. When a person is cited without a reference, it means that this review is the first account of the findings. We will stress that the methods used in these experiments, unless they are specifically described, were as close to the methods we have used in the past as it was possible for us to make them. Thus, if there are questions as to just how extensive the lesions were upon reconstruction, our past accounts of similarly treated preparations present an accurate portrayal of our latest anatomical results. Also, we believe that the data in the captions, in conjunction with the functions in the figures, will prove to be sufficient should our colleagues wish to make their own evaluations of statistical reliabilities. 


\section{EFFECTS OF SIMULTANEOUS BILATERAL ABLATIONS UPON LEARNING AND RELEARNING OF THE HABIT}

We begin with a finding of Horel et al. (1966) concerning the performances of posterior subjects that had either learned the black-white habit prior to surgery or had not been preoperatively trained $\left(\mathbf{R}_{\mathbf{1}}\right.$ vs. OL). The finding is summarized in Figure 3 and, as the accompanying schematic indicates, was obtained from rats that either learned or relearned the habit with both eyes. The fact that the functions are essentially the same confirmed, for our conditions, one of Lashley's (1935) basic observations. It showed that although a radical bilateral posterior ablation does not prevent relearning of the habit, posterior subjects exhibit no signs of postoperative retention of the habit.

Horel et al. (1966) also found that the rate of relearning is affected by bilateral anterior ablations (Figure 4). In addition, they observed that naive animals prepared with anterior ablations are slower to learn the habit after surgery (OL) than naive animals prepared with posterior ablations (Figure 5). The relative slowness of the naive subjects with anterior lesions to learn the habit appeared to be due to the fact that it took the subjects nearly eight trials to reach the 5/10 criterion. The naive subjects with posterior lesions showed no initial avoidance of the positive white door, but otherwise were not demonstrably different from the subjects with anterior lesions.

Since, as has been noted, anterior subjects also exhibit hypophagias, Horel et al. (1966) prepared another group of subjects which were then permitted to recover from the surgery for 8 weeks instead of 3

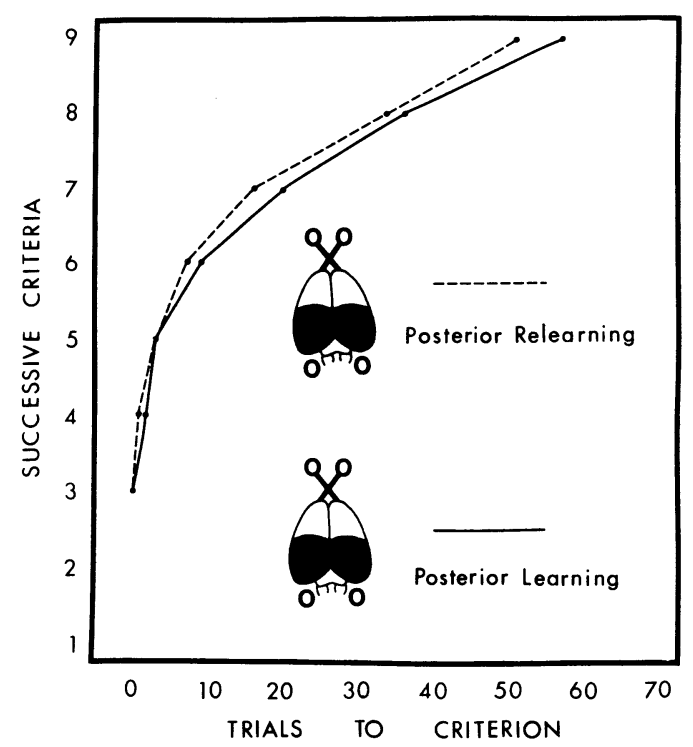

Figure 3. Solid: $\quad \mathbf{N}=33, \quad$ OL $=\mathbf{5 8 . 2} \pm \mathbf{5 . 7 6}$ Dashed: $\quad \mathbf{N}=33, \quad \mathbf{R}_{1}=51.1 \pm 4.81$

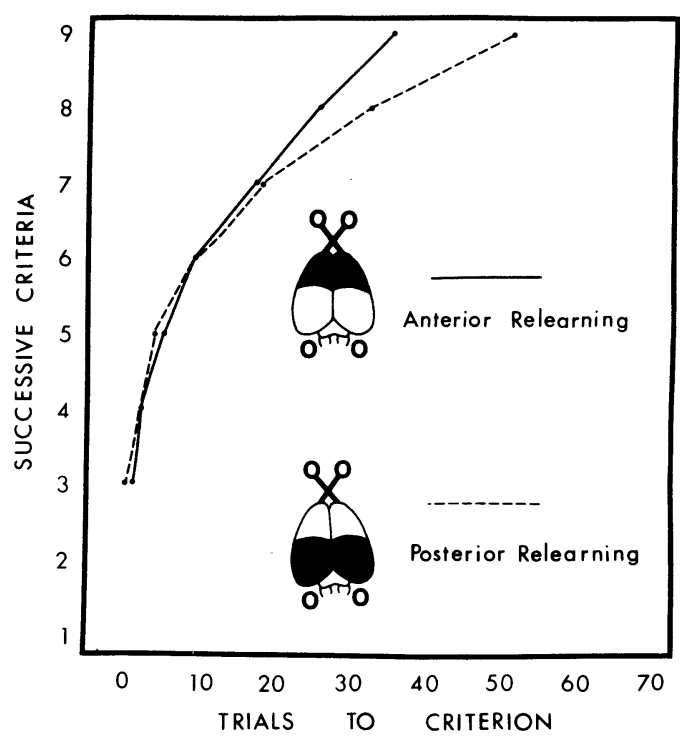

Figure 4. Solid: $\quad \mathbf{N}=35, \quad \mathbf{R}_{1}=35.0 \pm 3.08$ Dashed: $\quad N=33, \quad R_{1}=51.1 \pm 4.81$

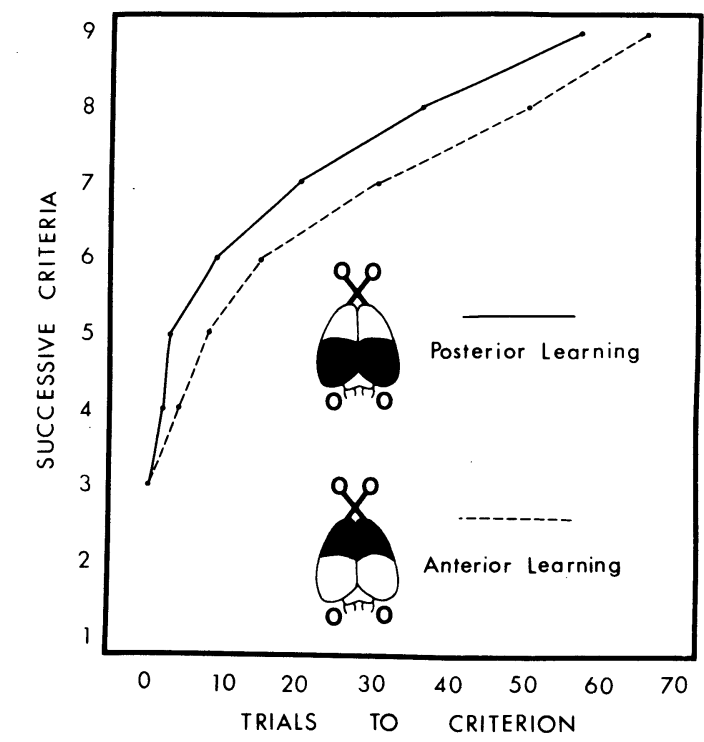

Figure 5. Solid: $\quad \mathbf{N}=33, \quad$ OL $=58.2 \pm 5.76$ Dashed: $\quad \mathbf{N}=35, \quad$ OL $=63.6 \pm 3.86$

weeks. As Figure 6 shows, the rate at which those subjects learned the black-white habit (OL) was essentially the same as the rate that was observed for subjects with short recovery times.

Horel et al. (1966) also studied the effects of successive combinations of anterior and posterior ablations. They found that if rats with anterior lesions were trained on the habit and were then subjected to second-stage posterior ablations, the animals relearned the habit $\left(\mathbf{R}_{1}\right)$ at the same rate as animals with first-stage posterior ablations (Figure 7). Moreover, they observed that if the two ablations were con- 


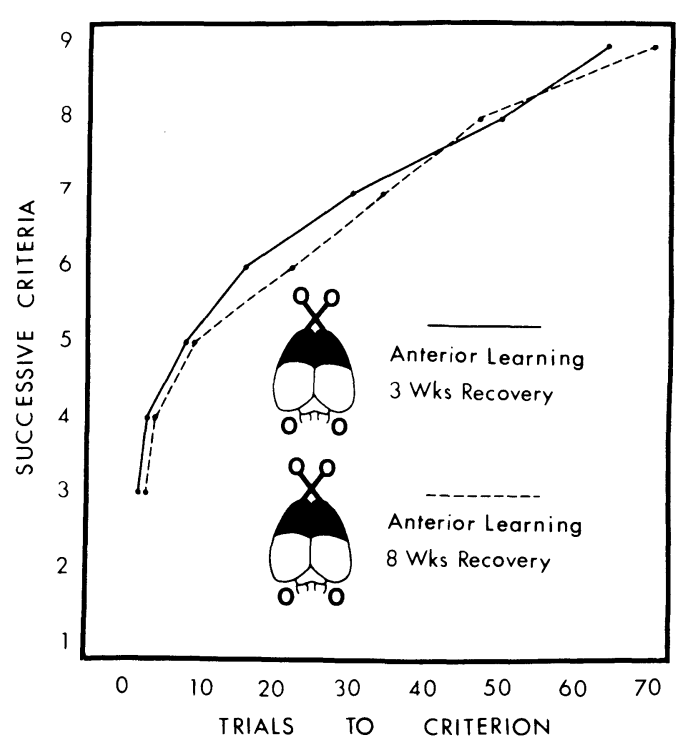

Figure 6. Solid: $\quad \mathbf{N}=35, \quad \mathbf{R}_{1}=65.0 \pm N / A$ Dashed: $\quad N=11, \quad R_{1}=72.0 \pm 9.20$

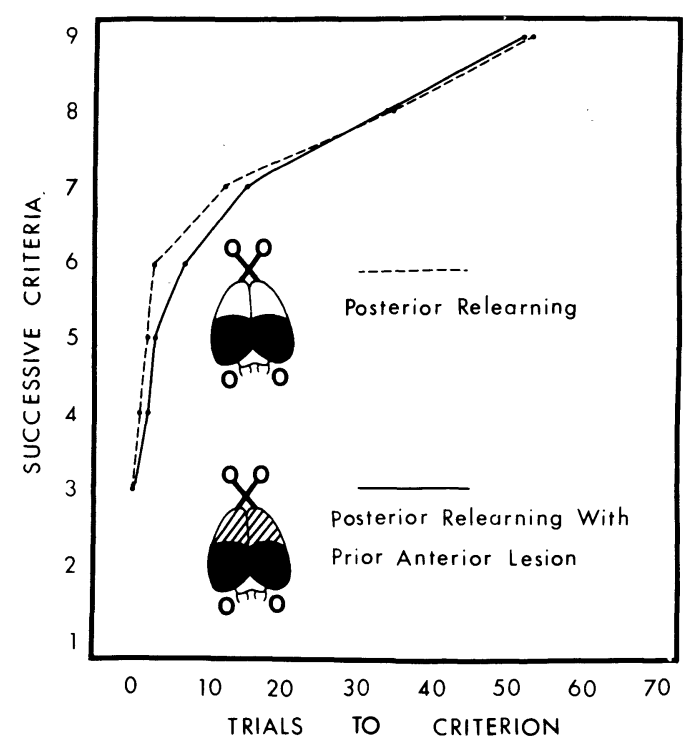

Figure 7. Solid: $\quad \mathbf{N}=\mathbf{3 5}, \quad \mathbf{R}_{\mathbf{1}}=\mathbf{5 0 . 0} \pm 7.18$ Dashed: $\quad N=33, \quad R_{1}=51.1 \pm 4.81$

ducted in the opposite order, relearning of the habit after second-stage anterior ablations occurred at a rate that was the same as the rate of relearning of the habit by subjects with first-stage anterior ablations (Figure 8). These results showed that the effects upon retention of either of the two extirpations are regionally specific and completely independent of the status of the rest of the cortex.

Next, Meyer, Yutzey, Dalby, and Meyer (1968) examined the effects of one-stage ablations of the entire dorsolateral isocortex. They found that their animals relearned the habit in 74 mean massed trials (Figure 9). Hence, they concluded that anterior lesions serve to enhance the deficits of subjects with lesions of the posterior cortex, but also that complete dorsolateral ablations have effects which are reasonably close to the sum of the effects of anterior and posterior ablations.

\section{THE NATURE OF THE DEFICITS PRODUCED BY POSTERIOR ABLATIONS}

We next addressed the question of why rats prepared with lesions of the posterior cortex should show no postoperative retention of a habit that they nonetheless are capable of learning. As we have

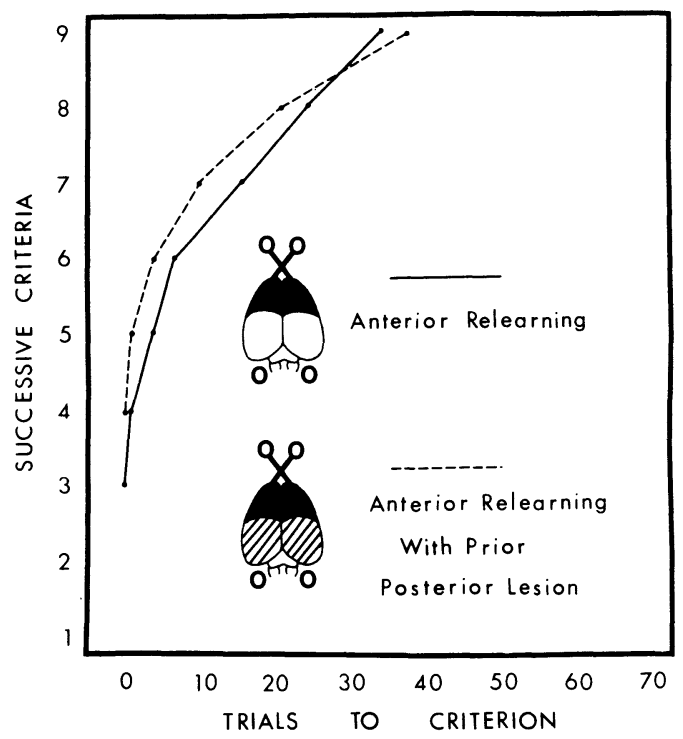

Figure 8. Solid: $\quad \mathbf{N}=35, \quad \mathbf{R}_{1}=35.0 \pm \mathbf{3 . 0 8}$ Dashed: $\quad \mathbf{N}=8, \quad R_{1}=37.0 \pm 10.98$

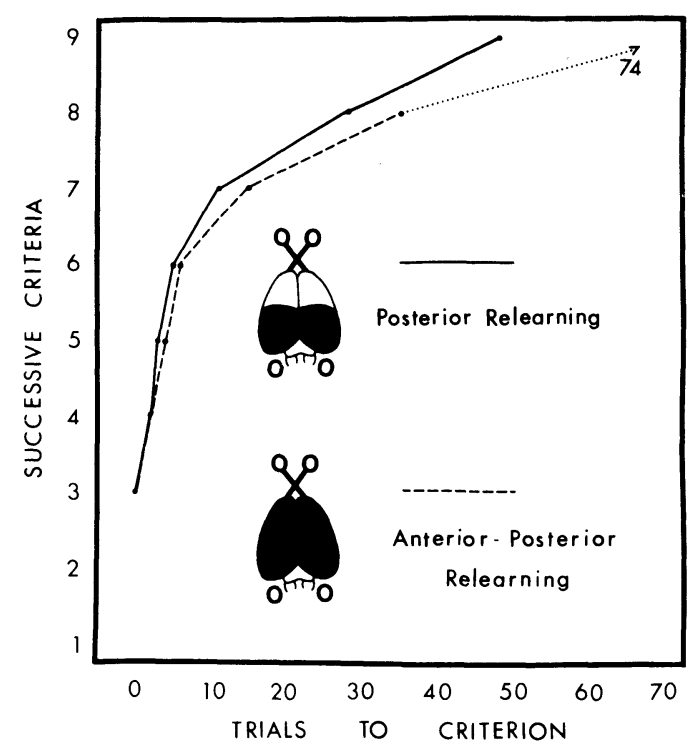

Figure 9. Solid: $\quad N=41, \quad R_{1}=48.1 \pm 4.50$ Dashed: $\quad \mathbf{N}=30, \quad \mathbf{R}_{1}=74.0 \pm 9.30$ 
observed, there were three major possibilities, and one was that the habit was learned by normal subjects as a visual-pattern habit. This interpretation has been offered by Cooper and his colleagues (Bauer \& Cooper, 1964; Cooper, Blochert, Gillespie, \& Miller, 1972). According to their theory, normal rats respond to such visual features as the edges and the corners of the doors used in black-white training and fail to form habits on the basis of intensitive differences between the stimuli. Then, when the posterior cortex is destroyed, the animals no longer see the features, and hence must learn an altogether new and different habit by responding to differences in flux.

We obtained two findings which seemed to be consistent with the theory. First, we observed that subjects prepared with radical bilateral posterior ablations are unable to learn pattern habits (Horel et al., 1966). Second, we observed that normal animals and subjects with posterior ablations respond in different ways to the cues that are present in the blackwhite training situation. Thus, normal rats, like anterior preparations, avoid the white door when they are first given training on the habit, but posterior subjects have no initial preferences whatever (Figure 10; Horel et al., 1966). Hence, perceptual changes unquestionably occur when the posterior cortex is destroyed, and the habits which are learned by posterior subjects are different in at least some respects from the habits which are learned by normal animals.

Next, in an experiment of Braun, Meyer, and Meyer (1966), we found that treatments with amphetamine would serve to facilitate relearning of the black-white habit by posteriorly decorticated subjects (Figure 11). The effect was obtained with doses of the drug that

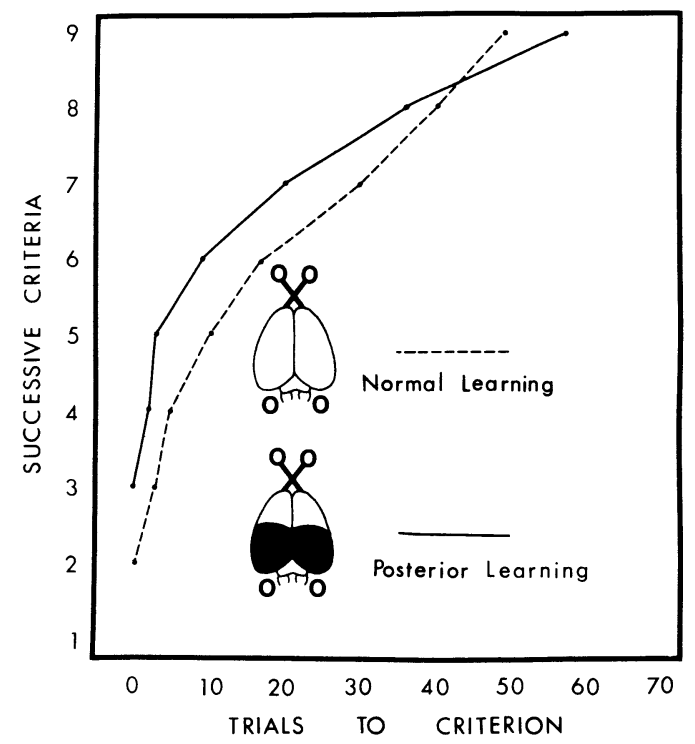

Figure 10. Solid: $\quad \mathbf{N}=33, \quad$ OL $=58.2 \pm 5.76$ Dashed: $\quad N=90, \quad$ OL $=49.6 \pm 1.90$

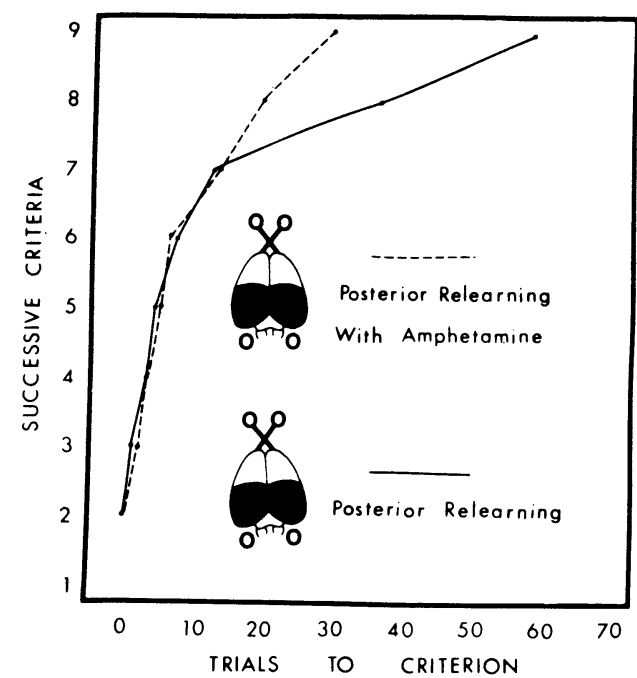

Figure 11. Solid: $\quad N=13, \quad R_{1}=58.0 \pm N / A$

Dashed: $\quad \mathbf{N}=31, \quad \mathbf{R}_{1}=30.0 \pm N / A$

failed to yield acceleration of the rate at which the black-white habit is learned (OL) by preoperatively naive bilateral posterior preparations (Figure 12). Accordingly, the findings implied that if the theory of Cooper was essentially correct, the treatments had permitted the subjects which were trained before the operation to see visual features that are not ordinarily perceptible by animals whose visual cortex is destroyed.

We tested that idea in an experiment of Jonason, Lauber, Robbins, Meyer, and Meyer (1970). Therein, we showed once again that many subjects with posterior lesions, if treated with amphetamine, will rapidly relearn the black-white discrimination habit. Also, we found that treatments have, at most, a very small effect upon the rate of relearning of the habit by anterior preparations. And third, we observed that treatments with the drug which will serve to reinstate performance of the black-white habit by posterior preparations will not permit the subjects to exhibit retention of a previously established oblique-stripes discrimination habit.

The last of these conclusions was based upon comparisons between 12 saline-injected animals and 14 subjects which were treated with amphetamine. Both groups were trained before the operation, and in the last 50 of 200 training trials they performed the habit at a level of $80 \%$ correct responses. After operation, the control subjects performed the habit in successive 50 -trial blocks at levels of $49 \%, 44 \%, 42 \%, 46 \%$, $48 \%$, and $48 \%$ correct responses. The amphetaminetreated subjects performed the habit in successive 50 -trial blocks at levels of $40 \%, 44 \%, 45 \%, 45 \%$, $44 \%$, and $45 \%$ correct responses. Thus there were no signs whatever of a trend toward improvement of performance of the visual-pattern habit in either the treated or the untreated posterior subjects, although 


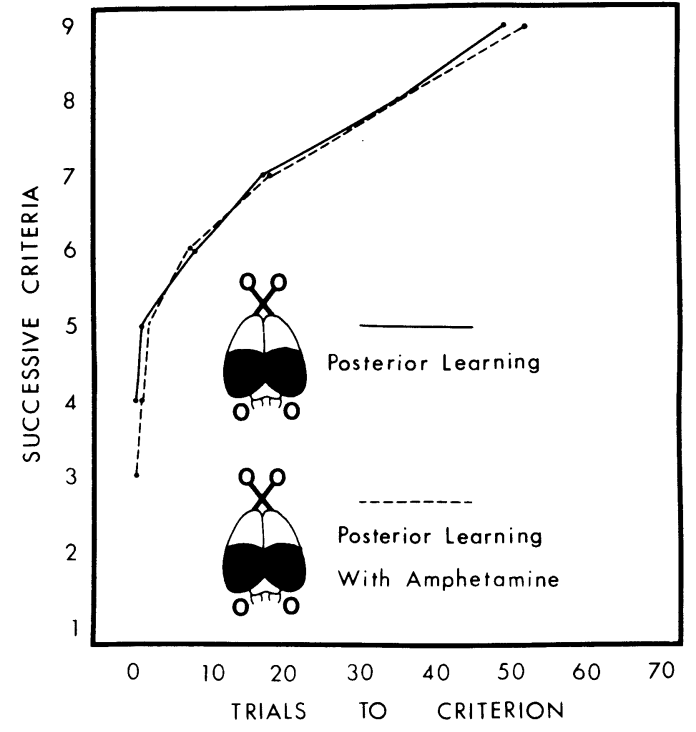

Figure 12. Solid: $\quad N=13, \quad$ OL $=49.0 \pm N / A$ Dashed: $\quad \mathbf{N}=15, \quad$ OL $=53.0 \pm N / A$

the treated subjects received a dose of amphetamine $(1 \mathrm{mg} / \mathrm{kg})$ which Braun et al. (1966) had shown would effect a rapid reinstatement of performance of the black-white habit.

Accordingly, our findings were evidently consistent with the notion that although normal animals respond to visuospatial cues when they are trained on the black-white problem, they must also learn habits which are based upon cues that can still be detected by bilateral posterior preparations. Therefore, they disproved the theory of Cooper and showed, in addition, that posterior ablations do not produce complete impairments of retention of the black-white habit because they obliterate preoperatively established associative substrates for the habit. Hence we concluded that the losses of retention are due, at least in part, to impairments of memorial access, and that treatments with amphetamine will serve to correct the amnestic component of the posterior subject's deficits (Meyer, 1972).

Our conclusion that memories for the black-white habit are not destroyed by lesions of the posterior cortex has since been validated by a study of LeVere and Morlock (1973). They based their experiment upon the supposition that if posterior lesions eradicate preoperatively established memories for the habit, then posterior subjects should be able to learn reversals of preoperatively established habits at the rate at which they relearn a habit that they learned before the surgery. Their findings showed, instead, that cue-reward reversals retard postoperative relearning, and will yield that effect even though posterior subjects exhibit no postoperative retention whatsoever of a habit that they learned as normal subjects. Moreover, the amounts of interference which were noted when the subjects were retrained on reversals were so large as to suggest that the latent substrates had not been affected to any great extent by ablations of the posterior cortex (Figure 13).

\section{EFFECTS UPON RETENTION OF TWO-STAGE SERIAL ABLATIONS OF THE POSTERIOR CORTEX}

From the foregoing studies, it was clear that bilateral ablations of the posterior cortex do not suppress retention of the black-white habit by destroying either all or some critical component of the substrates established by preoperative training on the task. But the fact still remained that the losses of retention are nonetheless essentially complete when the tests for postoperative relearning of the habit are conducted with untreated subjects. Hence our next problem was to try to understand the bases of the failures of performance, and we first approached the problem by studying the effects of serial posterior extirpations.

The fundamental question was whether an ablation of the left or the right posterior cortex would serve to initiate compensatory changes in cerebral organization such that the habit would then be retained after subsequent ablations of the contralateral posterior cortex. It had long been established through experiments of Ades and Raab (1946), Raab and Ades (1946), Stewart and Ades (1951), and Pavlov (1927) that classically conditioned responses which are lost after one-stage ablations of cortical systems are frequently elicitable in animals subjected to serial extirpations of the same central neural mechanisms. In

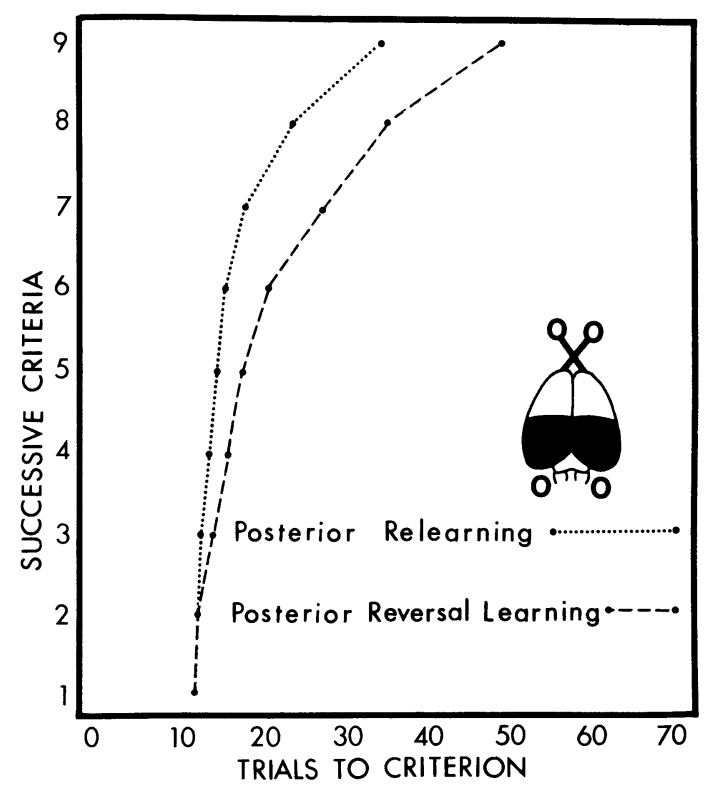

Figure 13. Synopsis of the findings of LeVere and Morlock (1973). 
that connection, we had also found that rats, if conditioned by active-avoidance procedures to respond to the onset of light, will exhibit retention of the CAR after two-stage serial posterior ablations if, in the interval between the operations, they are kept in illuminated cages (Meyer, Isaac, \& Maher, 1958). Hence we thought it likely that the black-white habit, and particularly if learned for shock avoidance, would also be relearned with at least some savings by twostage posterior preparations.

However, before we undertook our own studies, Thompson (1960) had examined the question, and had found that retention of the black-white habit was no less affected by serial than by one-stage bilateral posterior ablations. But Thompson did observe that if two-stage subjects were given interoperative training $\left(R_{1}\right)$, they then showed considerable amounts of savings if tested for ultimate retention of the habit $\left(R_{2}\right)$ following the second operation. Petrinovich and Bliss (1966) questioned these results, but Petrinovich and Carew (1969) confirmed them for animals prepared with reasonably extensive serial posterior ablations. Petrinovich and Carew then proposed that the findings of Meyer et al. (1958) for visual CARs were probably valid only for subjects with restricted posterior ablations.

We began our own investigations of the problem in experiments by Kircher, Braun, Meyer, and Meyer (1970). Therein, we confirmed the finding of Thompson (1960), and hence of Petrinovich and Carew (1969), that successive extirpations of the posterior cortex yield the same impairments of blackwhite retention as one-stage posterior extirpations. Also, we observed that this equivalence is not affected by such interoperative treatments as light or dark housing or twice-a-day injections of dl-amphetamine. Hence, inasmuch as the treatments had been shown to facilitate retention of light-discriminated CARs (Cole, Sullins, \& Isaac, 1967; Meyer et al., 1958), we concluded that the seeming discrepancy between the findings of Thompson (1960) and of Meyer et al. (1958) had arisen from task differences.

Our next step was replication of the finding of Thompson (1960) with respect to the ameliorative effects of formal interoperative training. The most important question was whether his result was due to overtraining on the task or, instead, was explicitly produced by further training of subjects with injuries to the brain. The question was studied by Glendenning (1972), who introduced the spaced-trial procedure, and hence was first obliged to show that the procedure would yield results comparable to those which are obtained when the massed-trial procedure is employed.

Glendenning (1972) demonstrated that the spacedtrial procedure permits normal rats to learn the black-white habit in approximately 25 trials, and also that, in doing so, they take 5 trials to reach $5 / 10$ criterion. Second, he showed that the spaced-trial procedure also permits posterior preparations to relearn the habit in approximately 25 trials (Figure 14). He compared these results with massed-trial findings of Horel et al. (1966) for similar groups of animals (Figure 15), and concluded that the outcomes were identical except for the fact that the spaced-trial procedure was twice as efficient as the massed-trial procedure. Hence we adopted the spaced-trial procedure for use in all our subsequent studies, and have thus far encountered no exception to the rule that a spaced-trial result, if doubled, will predict the outcome of a massed-trial inquiry.

Glendenning (1972) next confirmed the finding of

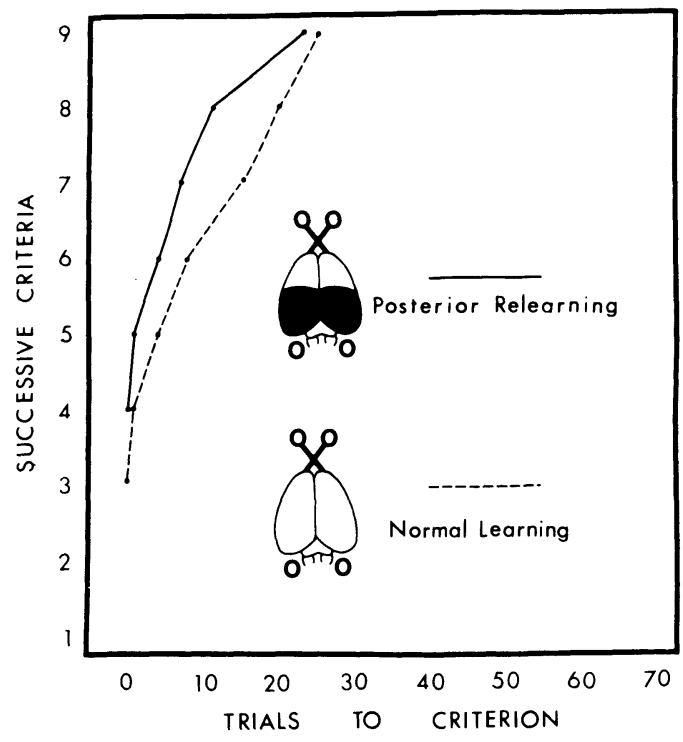

Figure 14. Solid: $\quad N=14, R_{1}=22.81 \pm 2.93$ Dashed: $\quad N=158, \quad O L=25.21 \pm N / A$

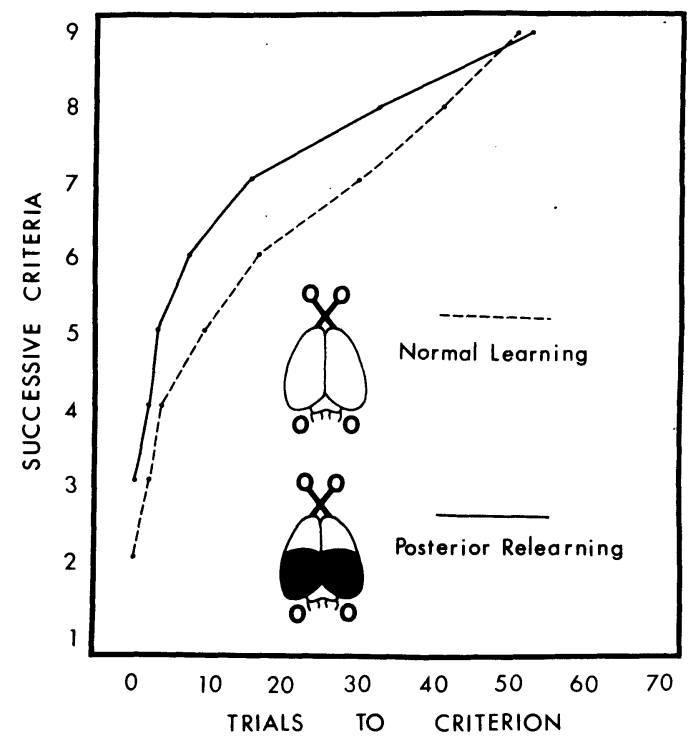

Figure 15. Solid: $\quad \mathbf{N}=33, \quad \mathbf{R}_{1}=\mathbf{5 1 . 1} \pm \mathbf{4 . 8 1}$ Dashed: $\quad \mathrm{N}=90, \quad$ OL $=49.6 \pm 1.90$ 
Thompson (1960) that rats prepared with two-stage posterior ablations will show some ultimate retention of the habit if given interoperative training. He found that it took a group of unilateral posterior subjects about 10 spaced trials to relearn the habit to the $9 / 10$ criterion. Then he gave the subjects 21 overtraining trials, and he found that following the second-stage ablations, the animals re-relearned the habit $\left(\mathbf{R}_{\mathbf{2}}\right)$ in approximately 13 trials, or in $\mathbf{1 0}$ fewer trials than were required for relearning of the habit by subjects prepared with one-stage bilateral posterior ablations (Figure 16). Also, with another group, he showed that the impairments of one-stage posterior preparations are not ameliorated if the animals are given 31 preoperative overtraining trials (Figure 17).

The latter observations confirmed, in principle, one of Lashley's earliest results (Lashley, 1921a). It showed, in conjunction with the other findings, that protection of ultimate retention of the habit can be induced by practice, but if, and only if, the practice is given to a subject with an injury to the brain. Also, inasmuch as Horel et al. (1966) had found that training given to anterior subjects does not induce protection of ultimate retention after second-stage posterior ablations, the findings of Glendenning suggested that the preexisting lesion must be of the posterior cortex. And, finally, it seemed that the protection of retention that is thereby conveyed is incomplete, for the $R_{2}$ impairments of the serial preparations were larger than their $\mathbf{R}_{1}$ impairments even though the subjects had been given interoperative overtraining (Figure 18).

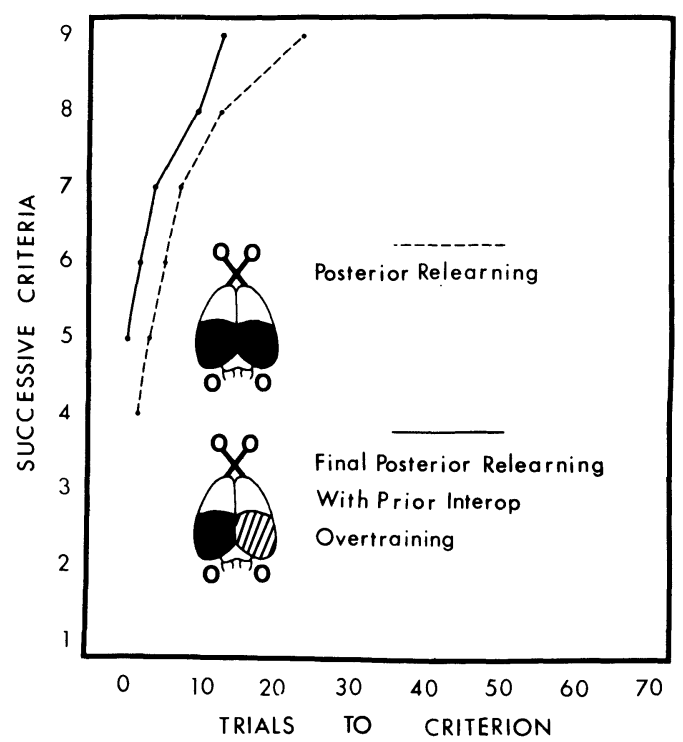

Figure 16. Solid: $\quad \mathbf{N}=16, \quad \mathbf{R}_{2}=13.4 \pm 3.35$ Dashed: $\quad \mathbf{N}=14, \quad \mathbf{R}_{1}=22.8 \pm 2.93$

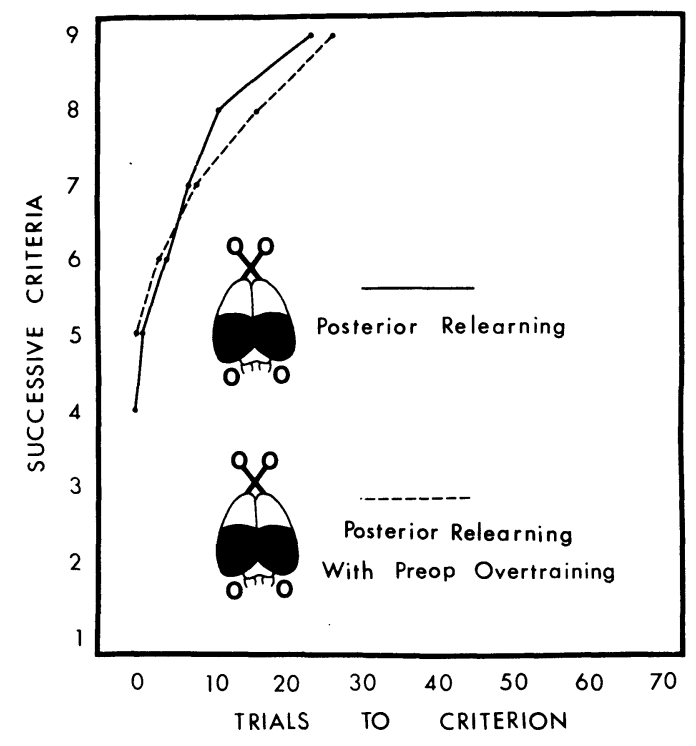

Figure 17. Solid: $\quad N=14, \quad R_{1}=22.8 \pm 2.93$ Dashed: $\quad N=15, \quad R_{1}=26.8 \pm 2.08$

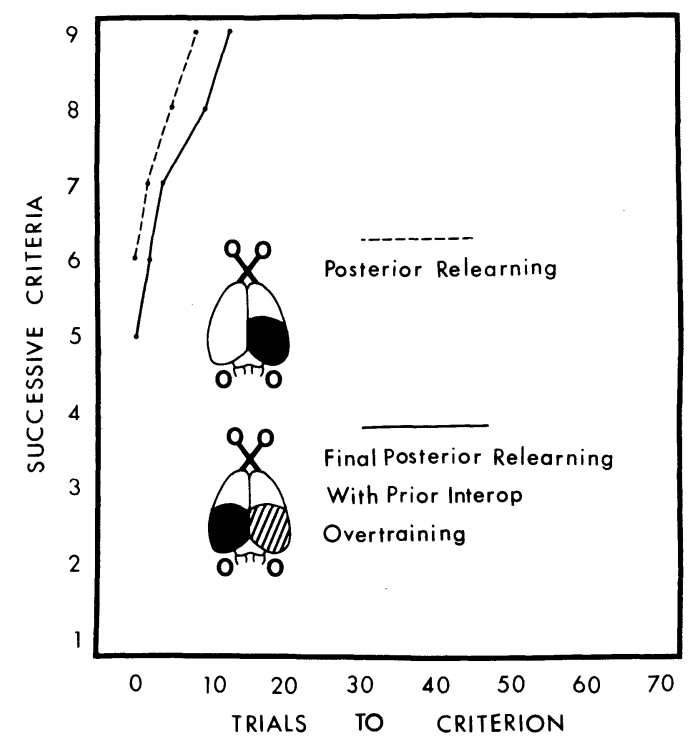

Figure 18. Solid: $\quad \mathbf{N}=16, \quad \mathbf{R}_{2}=13.4 \pm 3.35$ Dashed: $\quad N=16, \quad R_{1}=8.1 \pm 1.89$

\section{FORMULATION OF THE THEORY OF SUPPRESSION}

We believed, at that juncture, that our findings with respect to posterior subjects were consistent with the following ideas. When normal rats are trained on the black-white habit, associative substrates or engrams are formed through modifications of the properties of extraisocortical mechanisms. Concurrently, retrieval systems are developed which permit utilizations of the engrams, and are largely developed through modifications of cortically related 
mechanisms. Hence, when the posterior cortex is destroyed, the engrams survive the operation, but are then unavailable or inaccessible unless therapeutic steps are taken.

However, we were left with the question as to why retrieval is primarily a cortical function provided that the cortex is intact. At first, we believed that the answer was implicit in the finding of Horel et al. (1966) that, other things being equal, normal rats acquire the habit at a faster rate than animals with posterior lesions (cf. Figure 10). Essentially, we thought that if a subject possesses two potential systems for performance of the black-white habit, it will principally employ the system that permits it to learn the problem most efficiently. We interpreted the Thompson (1960) effect as being due to the fact that the first-stage ablations injure the cortically related mechanisms and hence, to a degree, will serve to reduce the otherwise-substantial differences between the efficiencies of subisocortical and isocortical retrieval processes. The subjects then no longer have a basis for a preferential utilization of the cortex, and under such conditions further training will develop alternative retrieval mechanisms.

Although the theory was reasonable and simple, it also was largely post hoc. Accordingly, we looked for a procedure that would test it, and were led to examine the effects upon retention of monocular occlusion during interoperative training in the Thompson (1960) paradigm. The experiments were part of the program of Glendenning (1972), and involved the use of small, black contact occluders of a type devised by Schuck and Coppola (1963). The occluders were hemispheric plastic cups which, when placed beneath a subject's eyelids, would then stay in place until removed at the end of each day of training on the task. In the figures to follow, if the data were collected while the subjects were monocularly occluded, the accompanying schematic shows the unoccluded eye as present and the other eye as absent.

In all of his experiments, Glendenning gave his subjects binocular preoperative training on the problem. Thereafter, the majority were then prepared with unilateral posterior lesions, and when they had recovered the subjects were retrained $\left(R_{1}\right)$ while wearing a monocular occluder. The animals were then reoperated for removal of the still-remaining contralateral posterior cortex, and then they were retested for ultimate retention $\left(\mathbf{R}_{2}\right)$ with both eyes open.

Glendenning observed that if the subjects were retrained while wearing an occluder that blocked the crossed visual pathway to the damaged hemisphere, the mean relearning score for the subjects $\left(R_{1}\right)$ was approximately 8 spaced trials. Second, he observed that when similarly prepared subjects were retrained with both eyes, the mean interoperative relearning score $\left(R_{1}\right)$ was also about 8 spaced trials (Figure 19).

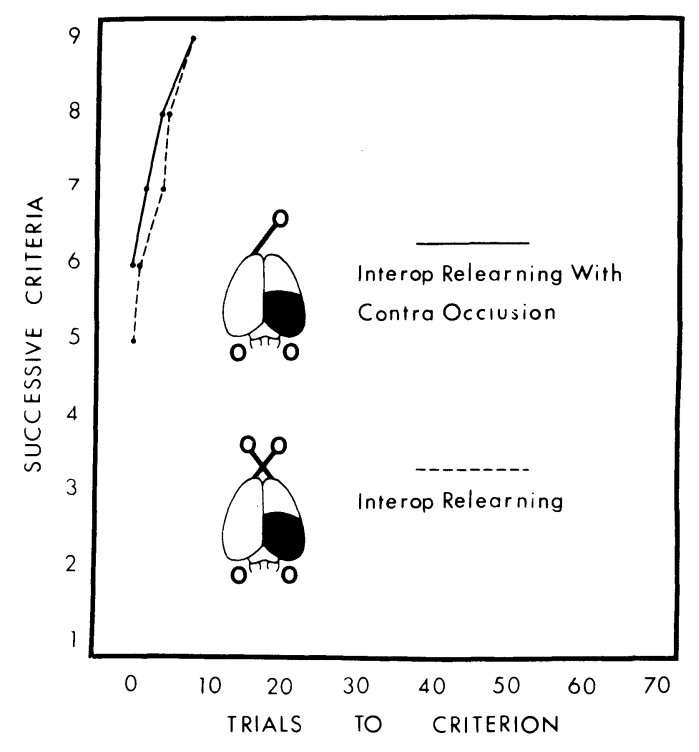

Figure 19. Solid: $\quad N=16, \quad R_{1}=8.1 \pm 1.89$ Dashed: $\quad N=19, \quad R_{1}=7.8 \pm 1.47$

Hence, it appeared that occlusion, by itself, had had no effect upon relearning, and Glendenning accordingly proceeded to compare the foregoing findings with results obtained from subjects which were retrained $\left(R_{1}\right)$ while the eye that was ipsilateral to the first-stage posterior ablation was occluded.

Glendenning suspected that the latter preparations, inasmuch as their monocular occluders served to block the crossed visual input to the undamaged posterior cortex, would be somewhat slower to relearn the habit than the unilateral posterior subjects which were retrained while wearing an occluder on the eye contralateral to the lesion. However, he was not quite prepared for the result he obtained, for he found that the ipsilaterally occluded subjects required more trials to relearn the habit than one-stage bilateral posterior preparations which were retrained with both eyes open (Figure 20). The finding was stunning, for Sheridan and Shrout (1965) had shown, in experiments with split-brain subjects, that the ipsilateral pathway to the posterior cortex can mediate visual-pattern habits. Despite that, Glendenning's observations suggested that a posterior quadrant of the cortex will not support retention of the blackwhite habit unless it is supplied with an input via the fibers of the crossed visual pathway.

The fact that occlusion had thus been shown to have a powerful effect upon retention provided Glendenning with a method for assessing the efficiency theory of preferential usage of cortical retrieval mechanisms. The prediction from the theory was clearly that the subjects which had shown interoperative retention of the habit $\left(R_{1}\right)$, and hence could be presumed to be employing the cortex during interoperative relearning, would suffer greater losses of 


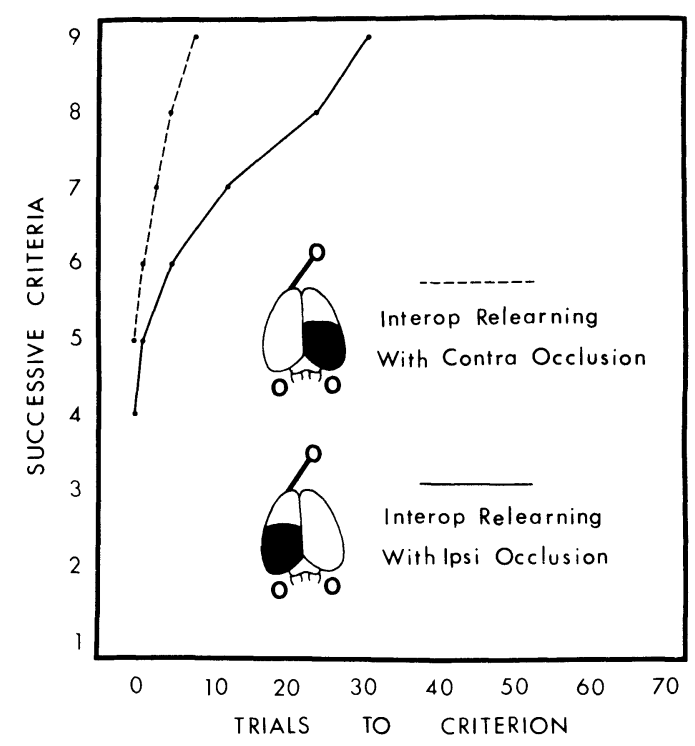

Figure 20. Solid: $\quad N=20, \quad R_{1}=30.8 \pm 3.42$ Dashed: $\quad N=19, \quad R_{1}=7.8 \pm 1.47$

ultimate retention $\left(\mathbf{R}_{\mathbf{2}}\right)$ following their second-stage posterior ablations than the subjects which behaved during $R_{1}$ retraining as if they had already been subjected to bilateral ablations of the posterior cortex. However, these predictions were not fulfilled, for the two groups' ultimate retention scores were 16 and 17 mean spaced trials, respectively (Figure 21). Thus, although the $\mathbf{R}_{\mathbf{1}}$ scores for the group were different by about $3: 1$, the second operations induced second deficits that seemed to be exactly the same.

Both of these $R_{2}$ scores were reminiscent of the $\mathbf{R}_{\mathbf{2}}$ scores for successive preparations which were given binocular interoperative overtraining on the

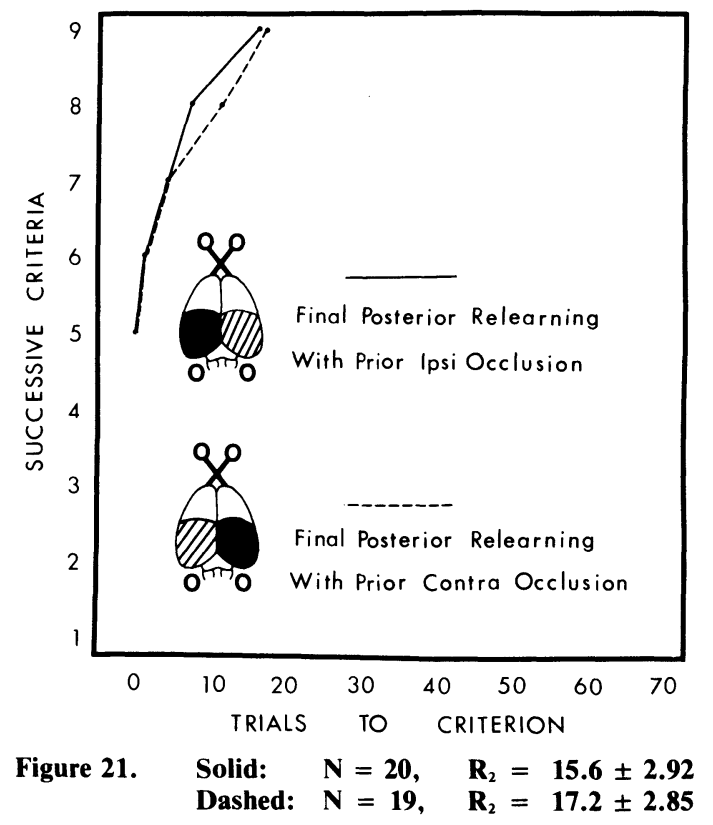

habit (cf. Figure 16). Also, they were virtually the same as the $R_{2}$ scores for contralaterally occluded subjects which were either retrained to criterion $(8$ trials) or else were given overtraining on the habit (31 trials) following their first-stage unilateral posterior surgeries (Figure 22). Hence it appeared that the effects of second-stage ablations of the posterior cortex were completely independent of the nature and extent of the subject's interoperative training. And, finally, the ultimate losses of retention were larger than the $R_{1}$ losses which are seen when unilateral posterior preparations are retrained on the habit while wearing an occluder which serves to block the crossed visual input to the previously damaged hemisphere (cf. Figure 20).

Glendenning interpreted his outcomes to mean that the cortex, if present, actively suppresses the development of systems which subserve the substitutive recoveries of the habit which are noted when one-stage posterior preparations are given retraining on the habit. He argued that a unilateral posterior lesion partially releases the suppression, and hence makes it possible for interoperative retraining to convey protection of ultimate retention. Also, he proposed that the continuing suppression limits the extent of the protection that can thereby be obtained, and by that hypothesis accounted for the fact that scores for ultimate retention $\left(\mathbf{R}_{\mathbf{2}}\right)$ of serially operated posterior subjects are worse than their $R_{1}$ scores. And, finally, he held that the suppression is not a function of whether the posterior cortex is involved in performance of the habit, and he drew that conclusion from the fact that the $\mathbf{R}_{2}$ scores were independent of whether the subjects exhibited retention of the habit when given interoperative training.

\section{A TEST OF THE THEORY OF SUPPRESSION}

In the Glendenning study, monocular occlusion was employed during interoperative retraining, but the animals initially acquired the habit and were tested for ultimate retention of the habit while neither of their eyes was occluded. Hence it was possible to think that the impairments of ultimate retention which were noted by Glendenning were functions of changes in the viewing conditions rather that of rigid limitations upon the process of postoperative recovery. Although that alternative appeared to be unlikely, we checked it in an unpublished study of G. D. Ritchie. In Ritchie's variation, occluders were used during both of the relearning phases although, as in all of our monocular studies, the animals were given binocular training prior to their first operations.

Ritchie's observations for rates of relearning after first-stage posterior ablations provided replications of a number of the principal findings of the 


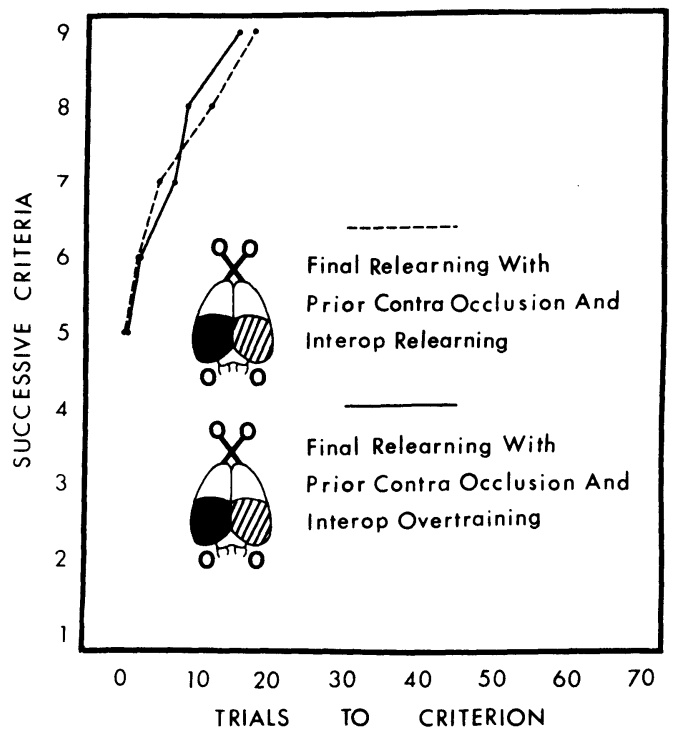

Figure 22. Solid: $\quad \mathbf{N}=16, \quad \mathbf{R}_{2}=15.8 \pm 2.72$ Dashed: $\quad \mathbf{N}=19, \quad \mathbf{R}_{2}=17.2 \pm 2.85$

Glendenning study. He found that unilateral posterior preparations which were retrained while wearing an occluder on the eye contralateral to the side of the ablation relearned the habit $\left(R_{1}\right)$ in a mean of 14 spaced trials. Thus the score was higher than Glendenning's score, but the interstudy difference was not statistically significant. The mean for the subjects from both experiments, with an overall $\mathrm{n}$ of 41 , was 11 mean trials, and the standard error of the mean was 1.7 trials.

Ritchie found that unilateral posterior subjects which were retrained with ipsilateral occlusion required a mean of 23 spaced trials to relearn the habit. That confirmed, in principle, Glendenning's observation that the side of the occlusion makes a very large difference in $\mathbf{R}_{\mathbf{1}}$ performance of the habit. Although Ritchie's score was 8 trials lower than Glendenning's, it was not significantly lower, and hence, once again, the two sets of data were combined. The mean for the $\mathbf{4 4}$ subjects of this kind which were trained in the two investigations was 28 trials, and the standard error of the mean was 2.4 trials. Figure 23 presents the relearning functions for the two combined groups of monocularly occluded animals, and shows that the impairment produced by occlusion of the crossed visual input to the undamaged hemisphere was evident at all of the above-chance criterial levels.

Ritchie's observation for ultimate retention confirmed one feature of the data that had prompted the statement of the theory of suppression. Thus he observed that his two groups of subjects, although their interoperative relearning rates were different by about $2: 1$, had impairments of ultimate retention $\left(R_{2}\right)$ following the second-stage posterior ablations which were wholly unrelated to their interoperative performances. The subjects which had relearned in 14 trials re-relearned in $31 / 26$ mean/median trials, and the subjects which had relearned in 23 trial rerelearned in 27/27 mean/median trials. Moreover, as is shown in Figure 24, the groups' performances were virtually the same at each of the 9 criteria.

Ritchie also replicated Glendenning's findings for one-stage posterior preparations. He found that it took his subjects $23 / 25$ mean/median spaced trials to relearn the habit to the $9 / 10$ criterion. That result compared very favorably indeed with Glendenning's 24/24 mean/median spaced trials, and was also within 1 trial of the mean for original learning of the

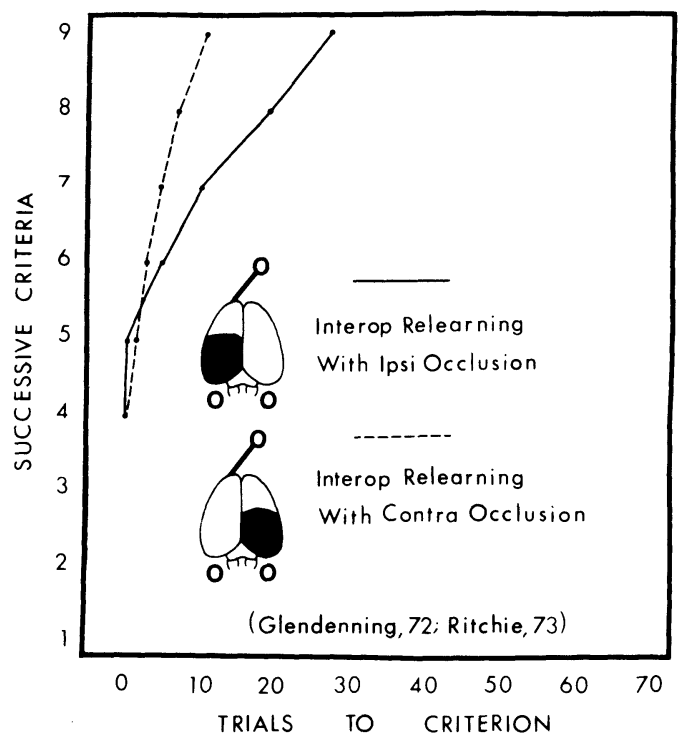

Figure 23. Solid: $\quad N=44, \quad R_{1}=28.0 \pm 2.40$ Dashed: $\quad N=41, \quad R_{1}=11.1 \pm 1.90$

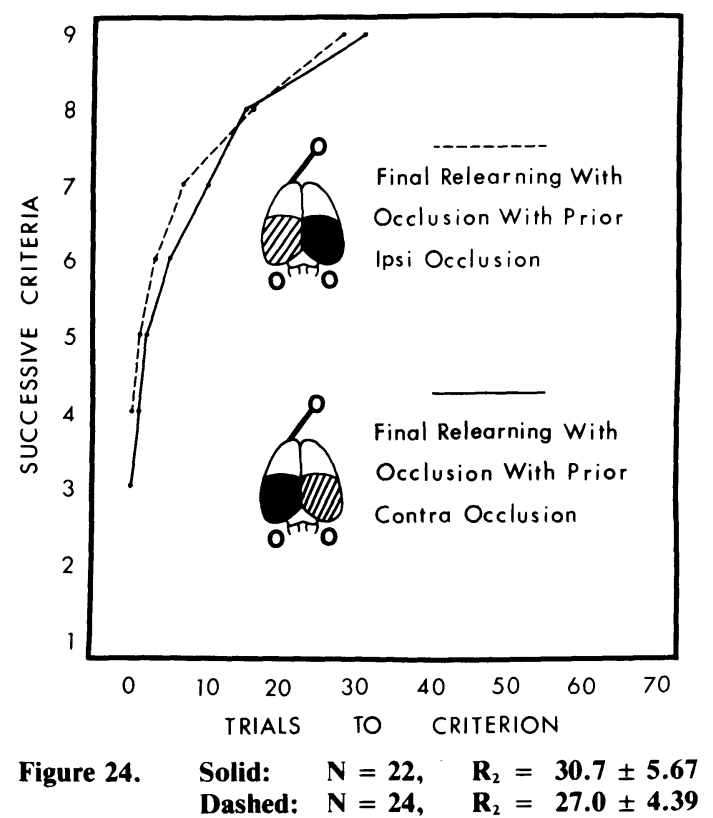


habit by the subjects prior to their bilateral operations.

However, Ritchie's findings posed an interesting problem, because they suggested that his serial preparations failed to exhibit protection of ultimate retention of the habit after they were given interoperative training on the habit. Thus the subjects had $\mathbf{R}_{\mathbf{2}}$ scores which were virtually the same, as was expected from the theory of suppression, but the scores were also approximately the same as the $R_{1}$ scores for binocular relearning of the habit by one-stage bilateral posterior preparations. Hence, since the $R_{1}$ results of the studies were not especially divergent, we were left with the question as to why Ritchie's $\mathbf{R}_{\mathbf{2}}$ scores were approximately 10 trials higher than the 16 to 17 mean spaced trials that it took Glendenning's serial preparations to re-relearn with neither eye occluded.

There had been no suggestion in the findings of Glendenning that occlusion by itself made a difference. This was checked by Ritchie and R. D. Kirvel in a study of five normal rats. The animals were given binocular training and then were retrained on two separate occasions while one of their eyes was occluded. The subject's mean/median relearning scores, which were measured at the same times that serial visual subjects received their interoperative training $\left(R_{1}\right)$, were $2 / 2$ spaced trials. The subjects' mean/ median re-relearning scores, which were measured at the same times that serial visual subjects received their tests for ultimate retention of the habit $\left(\mathbf{R}_{\mathbf{2}}\right)$, were $0 / 0$ spaced trials. From that, it was clear that occlusion of an eye did not affect retention of the habit provided that the tests of retention of the habit were carried out with normal animals.

But Ritchie next observed that monocular occlusion, although it had no obvious effect upon retention in subjects whose brains were intact, substantially inflated the relearning scores of subjects with one-stage bilateral posterior ablations. He found that simultaneous posterior preparations relearned the habit in $23 / 25$ mean/median trials if neither of their eyes was occluded, but that such subjects, if monocularly occluded, required an astonishing $38 / 33$ mean/median spaced trials to relearn the habit after surgery (Figure 25).

This finding was completely unexpected. However, it was crucial for the theory of suppression, for it meant that Ritchie's data for ultimate retention were consistent with the notion that his serial preparations had exhibited the Thompson effect. Thus the occluded one-stage subjects were slower to relearn the habit, and the difference was enough to account for the fact that Ritchie's $\mathbf{R}_{\mathbf{2}}$ scores were 10 trials higher than the scores that Glendenning had obtained from serial subjects which were given binocular tests for ultimate retention. Hence Ritchie's data were con-

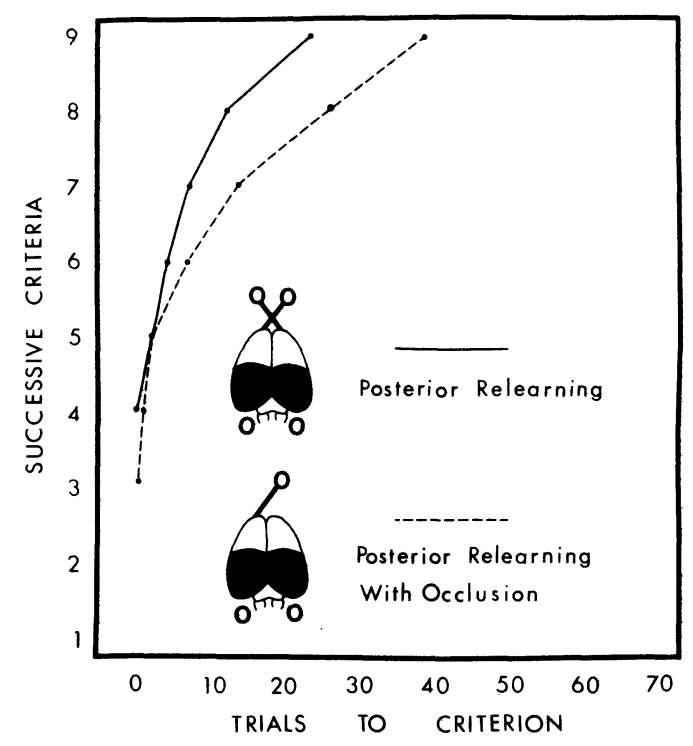

Figure 25. Solid: $\quad N=14, \quad R_{1}=22.8 \pm 2.93$ Dashed: $\quad N=14, \quad R_{1}=38.0 \pm 4.54$

sistent with two nontrivial predictions from the theory, namely, that the $R_{2}$ scores would be the same and that interoperative retraining $\left(R_{1}\right)$ would yield a measurable but incomplete protection of ultimate retention of the habit.

\section{EFFECTS OF MONOCULAR OCCLUSION UPON RETENTION BY ANTERIOR PREPARATIONS}

Glendenning (1972), in his studies of animals prepared with serial posterior ablations, utilized animals with unilateral anterior lesions as surgical controls. He found that his unilateral anterior subjects, if retrained with monocular occlusion, relearned the habit in approximately 8 mean spaced trials. The finding was virtually the same as that for subjects with unilateral posterior lesions which were then retrained with the eye contralateral to the undamaged cerebral hemisphere. Also, it was virtually the same as that for subjects prepared with unilateral posterior extirpations which were retrained on the habit after surgery with neither eye occluded. Accordingly, Glendenning concluded that ablations of any quadrant of the isocortex results in a minimal effect upon retention of 8-10 mean spaced trials.

Ritchie, in a second part of his investigation, carried out the same experiments. He also examined the effects upon retention of occlusion of the eye contralateral to a unilateral lesion of the anterior cerebral cortex. Ritchie observed, in agreement with Glendenning, that unilateral anterior animals relearn the habit in about 10 trials if the ipsilateral eye is occluded. He also observed that contralaterally 
occluded anterior subjects relearn in about 12 trials (Figure 26).

Next, Ritchie utilized the same groups of subjects to study the effects upon ultimate retention of second-stage ablations of the contralateral anterior cortex. Ritchie found that both groups of animals were able to re-relearn the habit very quickly, but he also observed that the subjects whose second-stage ablations were contralateral to the unoccluded eye were significantly more impaired than animals prepared with ipsilateral second-stage anterior ablations (Figure 27). However, the difference was relatively small, and hence, since the first-stage experiment had failed to yield effects of altered visual inputs, we initially dismissed the second observation as an outcome of sampling variations.

However, in studies carried out with Aileen Lee, Ritchie next encountered a variety of findings which led us to revise that conclusion. Each was a small, but consistent, indication that an anterior lesion, if combined with an ablation of other quadrants of the cerebral cortex, has its greatest effect upon relearning of the habit if placed contralateral to the eye with which the habit is relearned. In some of these experiments, the individual intergroup differences were not reliable, but the overall pattern of results was convincing because there were no exceptions to it.

The first of these studies was concerned with the effects of ablations of anterior and posterior quadrants which were either situated in the same hemisphere or else were contralateral to each other. Ritchie and Lee found that subjects prepared with homolateral anterior-posterior lesions required about 43 mean spaced trials to relearn the habit when they were retrained with the eye contralateral to the lesion. In contrast, animals with heterolateral lesions

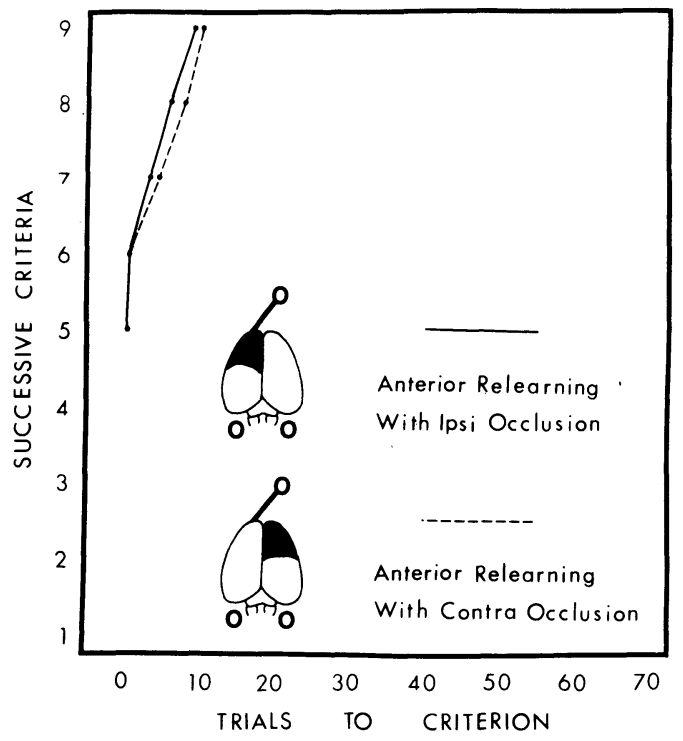

Figure 26. Solid: $\quad \mathbf{N}=20, \quad \mathbf{R}_{1}=10.1 \pm 1.94$ Dashed: $\quad N=21, \quad R_{1}=11.6 \pm 1.68$

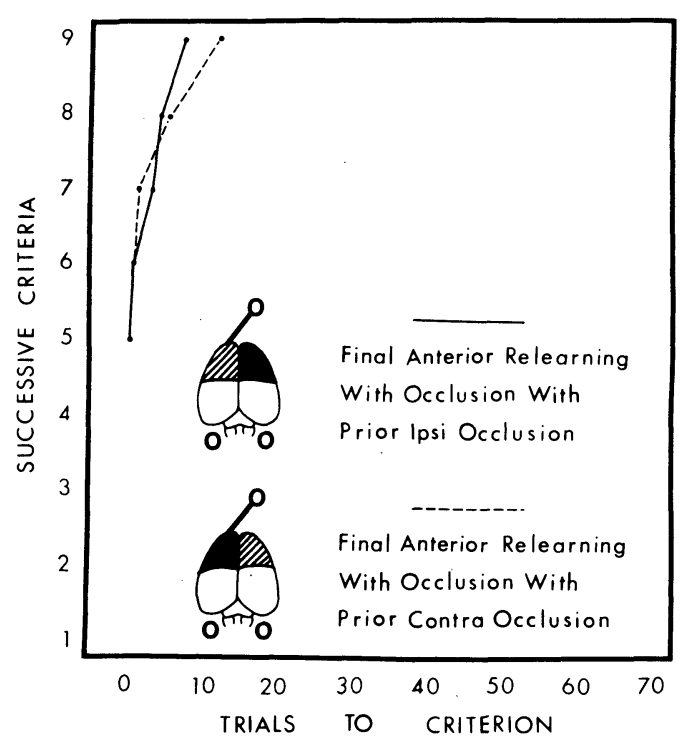

Figure 27. Solid: $\quad \mathbf{N}=\mathbf{2 0}, \quad \mathbf{R}_{2}=7.6 \pm 2.22$ Dashed: $\quad N=21, \quad R_{2}=14.3 \pm 2.26$

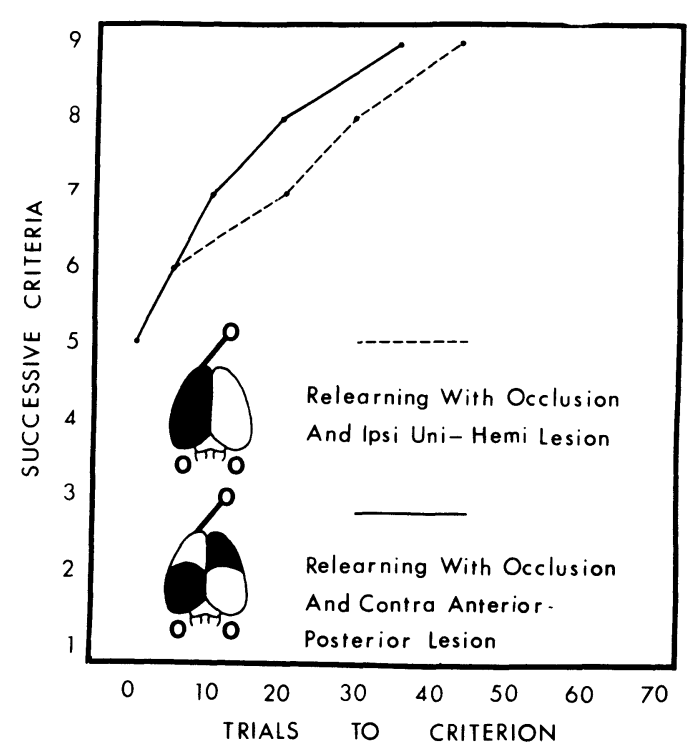

Figure 28. Solid: $\quad N=11, \quad R_{1}=35.0 \pm 6.11$ Dashed: $\quad N=14, \quad R_{1}=43.0 \pm 5.28$

of a pattern such that the anterior lesion was ipsilateral to the open eye and the posterior lesion was contralateral to the open eye relearned the habit in approximately 35 trials (Figure 28). A converse effect was observed in comparisons between homolateral and heterolateral subjects which were retrained with the opposite eye, for the homolateral subjects relearned the habit in 18 trials, or 9 fewer than the heterolateral subjects (Figure 29). Hence, in both instances, the consequence of adding an anterior lesion was greatest when the anterior lesion was contralateral to the open eye.

The four groups of animals were next reoperated, and the second-stage ablations completed the re- 


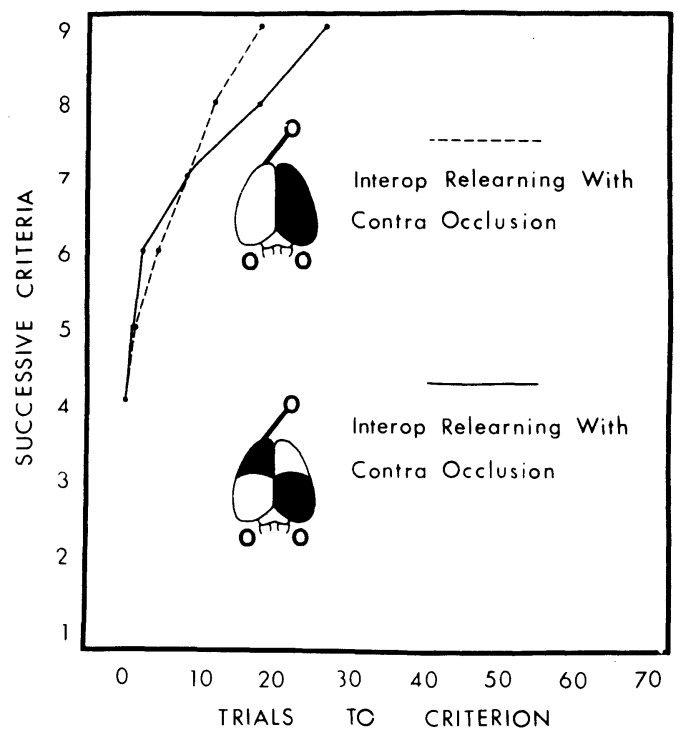

Figure 29. Solid: $\quad N=14, \quad R_{1}=27.0 \pm 3.48$ Dashed: $\quad N=11, \quad R_{1}=18.0 \pm 3.62$

movals of the still-intact posterior quadrants of the dorsal pallial cortex. The subjects thus were left with anterior quadrants which, during re-relearning, were either ipsilateral to or contralateral to the open eye. Lee and Ritchie found that when the second-stage ablations removed the visual cortex that was contralateral to the open eye, the habit was re-relearned in 41 trials if the contralateral anterior quadrant was intact, but in 62 trials if the ipsilateral anterior quadrant was intact (Figure 30). Also, they observed that when the second-stage ablations destroyed the visual quadrant that was ipsilateral to the open eye, the habit was relearned in 24 trials if the still-remaining anterior quadrant was opposite the open eye, but that 54 trials were required for re-relearning if the stillremaining anterior quadrant was ipsilateral to the open eye (Figure 31 ).

Lee and Ritchie also studied the effects of onestage ablations which destroyed three quadrants of the cortex. The outcomes, curiously, were not very different from the $\mathbf{R}_{\mathbf{2}}$ scores for animals prepared with comparable two-stage ablations, and the performances of subjects with intact posterior quadrants were not very different from those of preparations with intact homolateral anterior quadrants (Figures 32 and 33). But the findings, once again, indicated that the habit is relearned more rapidly by subjects with remaining anterior quadrants if the quadrants are opposite the eye that is used in retraining.

In a subsequent study, Glendenning and Kirvel examined the effects of monocular occlusion upon retention of visual-pattern habits by subjects prepared with unilateral posterior or anterior abla- tions. The task was the oblique-stripes discrimination problem that was previously employed by Horel et al. (1966) and also by Jonason et al. (1970). The subjects first were given binocular training with spaced-trial procedures and learned the pattern habit (OL) in a mean of 41 trials. They then were operated and tested for retention while wearing an occluder that was either on the eye contralateral to or ipsilateral to the cortical ablation. As Figures 34 and 35 show, subjects with unilateral anterior lesions or posterior lesions can relearn the visual pattern habit if monocularly occluded, and for reasons which we

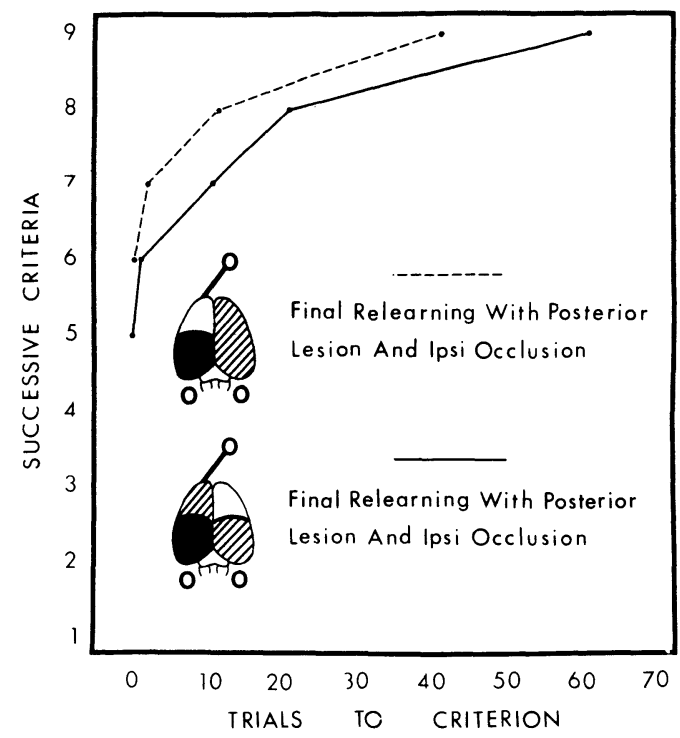

Figure 30. Solid: $\quad N=14, \quad R_{2}=62.0 \pm 9.03$ Dashed: $\quad \mathbf{N}=11, \quad \mathbf{R}_{2}=41.0 \pm 10.58$

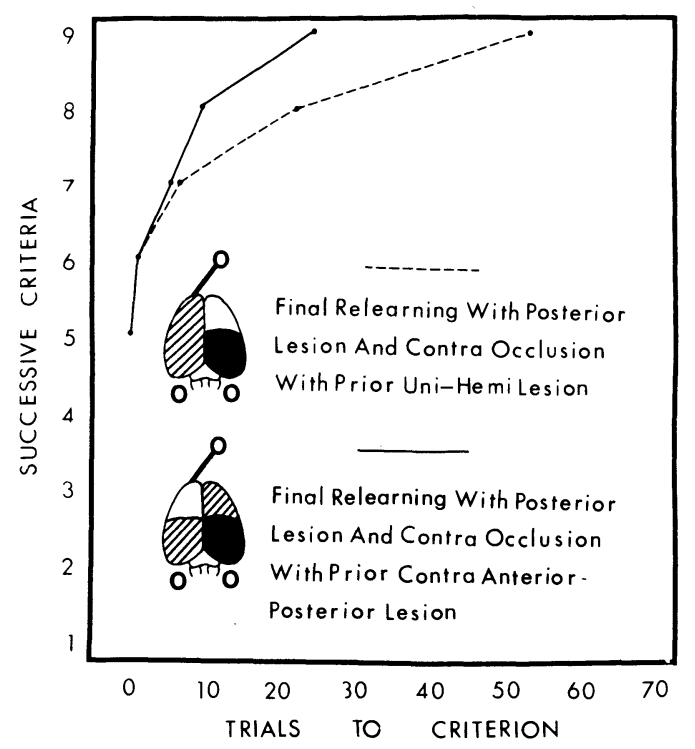

Figure 31. Solid: $\quad N=11, \quad R_{2}=24.0 \pm 6.44$ Dashed: $\quad N=14, \quad R_{2}=54.0 \pm 10.99$ 


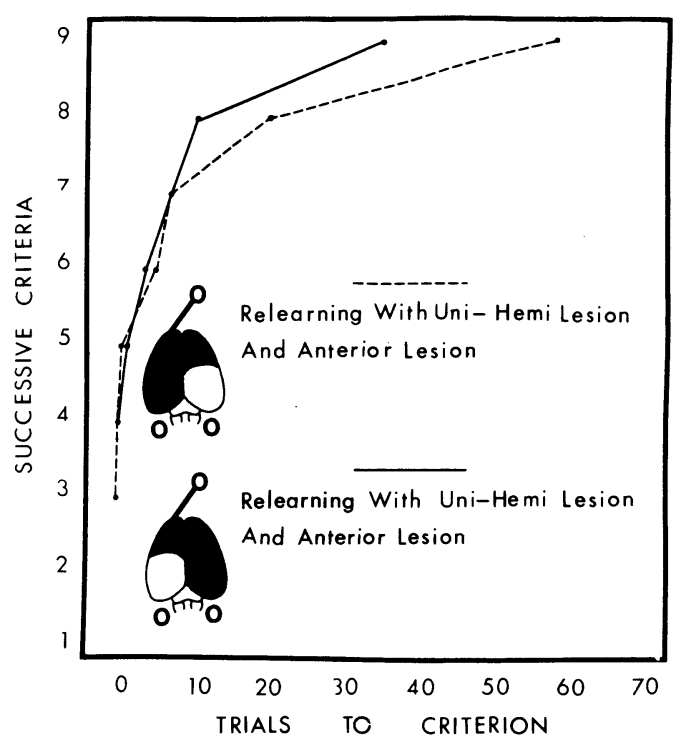

Figure 32. Solid: $\quad \mathbf{N}=12, \quad \mathbf{R}_{1}=35.8 \pm 8.23$ Dashed: $\quad N=12, \quad R_{1}=58.8 \pm 7.46$

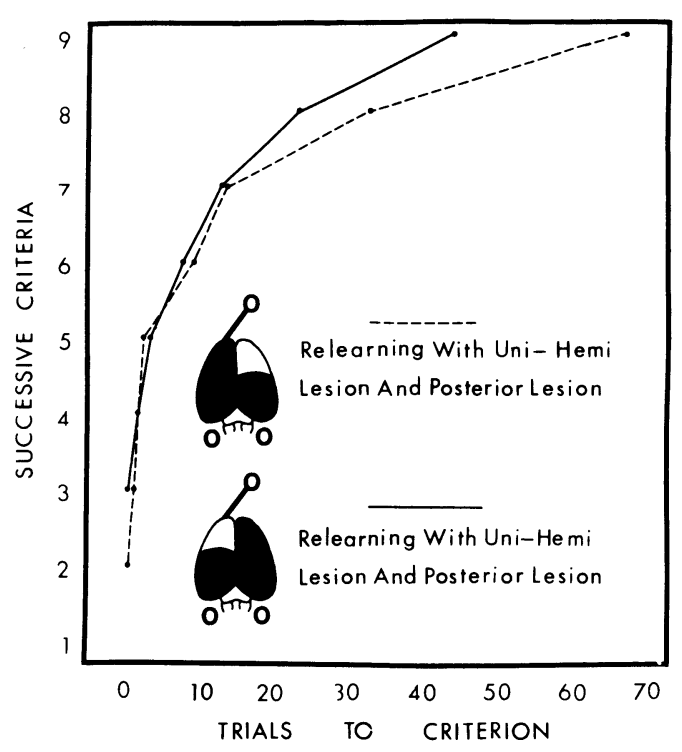

Figure 33. Solid: $\quad \mathbf{N}=13, \quad \mathbf{R}_{1}=43.5 \pm 7.37$ Dashed: $\quad N=13, \quad R_{1}=66.6 \pm 12.74$

do not understand as yet, the rate of relearnirig of the pattern habit by ipsilaterally occluded unilateral posterior subjects is approximately as fast as the rate at which the black-white habit is relearned by such subjects. However, both anterior and posterior subjects are faster to relearn the visual pattern habit if retrained while wearing a monocular occluder that blocks the crossed visual input to the damaged hemisphere. Accordingly, in seven out of eight investigations, we found that anterior ablations produce effects which evidently are visually specific, although different from the visually specific deficits that posterior lesions bring about.

\section{A SECOND TEST OF THE THEORY OF SUPPRESSION}

The foregoing studies had a secondary purpose, which was gathering of control information for a subsequent and rigorous examination of a feature of the theory of suppression. As we noted earlier, Glendenning (1972) proposed that the cortex, if present, has suppressive effects regardless of whether it is actually involved in performance of the blackwhite habit. He based that conclusion upon his observation that unilateral posterior subjects, if retrained with occlusion of the crossed visual input to the undamaged cerebral hemisphere, fail to exhibit

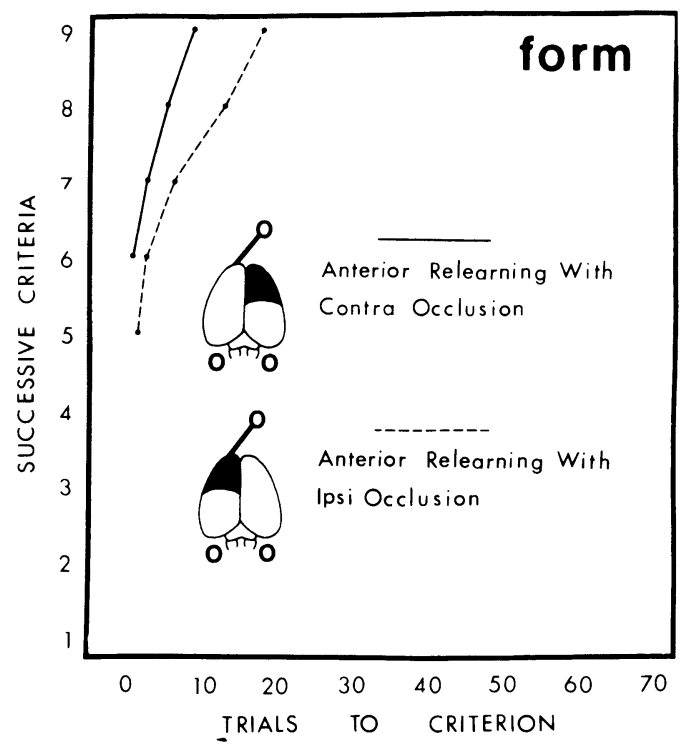

Figure 34. Solid: $\quad \mathbf{N}=\mathbf{2 0}, \quad \mathbf{R}_{1}=\mathbf{8 . 0} \pm \mathbf{1 . 9 5}$ Dashed: $\quad N=18, \quad R_{1}=17.0 \pm 3.06$

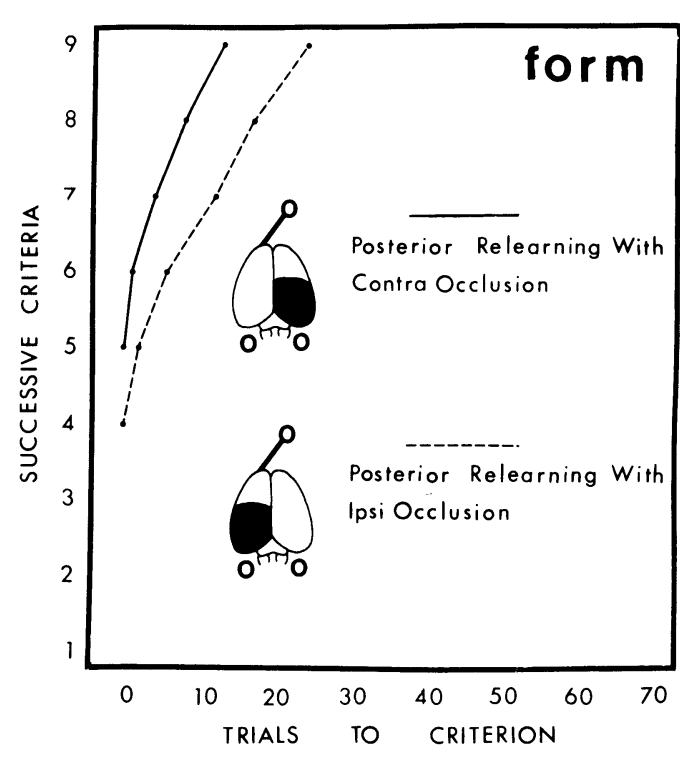

Figure 35. Solid: $\quad N=21, \quad R_{1}=13.0 \pm 2.16$ Dashed: $\quad N=29, \quad R_{1}=24.0 \pm 2.50$ 
interoperative retention $\left(R_{1}\right)$ but nonetheless will not, if interoperatively retrained, obtain more protection of ultimate retention $\left(R_{2}\right)$ than that which is conveyed by interoperative retraining of unilateral subjects whose $\mathbf{R}_{1}$ performances show that they are still employing their residual posterior cortical systems.

What we sought was an independent proof of his conclusion that occlusion of the crossed visual input does, in fact, prevent the participation of an undamaged quadrant of the posterior cortex in postoperative performance of the habit. We already knew, from the study of Ritchie, that Glendenning's observation that subjects thus prepared are unable to relearn the habit with postoperative transfer was completely correct. Moreover, although Ritchie had also observed that one-stage bilateral posterior preparations, if monocularly occluded, require about $38 / 33$ mean/median spaced trials to relearn the habit, Ritchie and Lee had subsequently found that heterolateral anterior-posterior subjects, if retrained with occlusion of the eye ipsilateral to the unilateral posterior lesion, have reasonably comparable impairments of retention of the habit. Hence all our findings were consistent with the view that the uncrossed input to a posterior quadrant will not permit the systems related to the quadrant to mediate performance of the habit, but we thought that the concept required evaluation by direct assessments of the consequences of a second-stage ablation of a denervated posterior quadrant.

Our approach to the problem was as follows. We propesed to destroy the uncrossed input to a posterior quadrant of the cortex by severing the ipsilateral optic tract and then, by combining that procedure with occlusion of the eye contralateral to the quadrant, to restrict the visual input to the opposite cerebral hemisphere. The question was whether a subject thus prepared, and also prepared with a posterior lesion of the opposite cerebral hemisphere, would, if given interoperative retraining $\left(R_{1}\right)$, exhibit an impairment of ultimate retention $\left(R_{2}\right)$ following a second-stage removal of the still-intact, but denervated, posterior quadrant. The prediction from the theory of suppression was that $R_{2}$ impairments would be found which would take some 27 trials to overcome if the $\mathbf{R}_{\mathbf{2}}$ tests were conducted with monocular occlusion. The alternative prediction was that the impairments would be overcome in no more than 10 trials, that is, in the minimal number of trials that it takes a subject with a quadrant ablation of any kind to relearn the black-white habit after surgery.

The optic tract sections were accomplished with stereotaxic methods. With the kind cooperation of our colleague, Gary Berntson, we controlled the placements of the electrodes by using them to pick up action potentials evoked in the tract by brief flashes of light. We expected the lesions to damage other nearby structures, and hence we selected placements which we hoped would limit the encroachments to components of the amygdala. We did so because, in studies that have been reported by Kleiner, Meyer, and Meyer (1967), we had found that radical amygdalar ablations have no prolonged effects upon postoperative retention of the blackwhite discrimination habit.

We utilized behavioral procedures to assess the functional completeness of the sections. First, we determined the effects of tract lesions upon the postoperative relearning rates of subjects which otherwise were normal animals. These subjects wore occluders on the eye contralateral to the side of the optic-tract lesion, and hence were presumably relearning the habit with the crossed visual pathway to the undamaged cerebral hemisphere. The rate of relearning for subjects thus prepared proved to be approximately the same as that for subjects with homolateral anterior-posterior cortical ablations (Figure 36). Hence, it appeared that visual denervation of the hemisphere ipsilateral to the open eye has much the same effect upon relearning of the habit as does extirpation of the cortex of the same hemisphere.

The next important question was whether that equivalence of outcomes had been coincidental. It seemed not to be from the results obtained with one further group. For that group, the surgical procedure consisted of a unilateral section of one optic tract and a simultaneous ablation of the contralateral posterior cortical quadrant. The animals were subsequently tested for retention with the eye contralateral to the cortical ablation, and their rate of relearning was then compared with that of rats which had been prepared with one-stage three-quadrant lesions of the ipsilateral anterior-posterior cortex

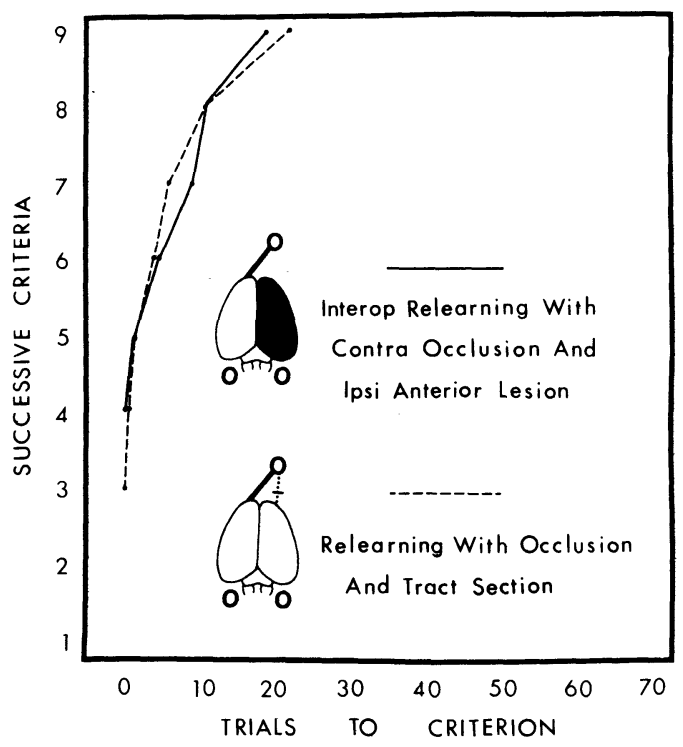

Figure 36. Solid: $\quad N=11, \quad R_{1}=18.0 \pm 3.62$ Dashed: $\quad N=15, \quad R_{1}=21.0 \pm 3.10$ 
and the contralateral posterior cortex (Figure 37). The groups' mean performances were virtually the same at each of the nine criteria and hence, once again, the effect of denervation of the ipsilateral cortex appeared to be the same as the effect of removal of the cortex.

The unilateral posterior-tract preparations were next subjected to a second-stage ablation of the previously denervated quadrant of the cortex. The animals were then re-retrained on the habit while wearing a monocular occluder, and hence the appropriate control group was taken from the previous experiment of Ritchie. As we have observed, the expectation from the theory of suppression was that

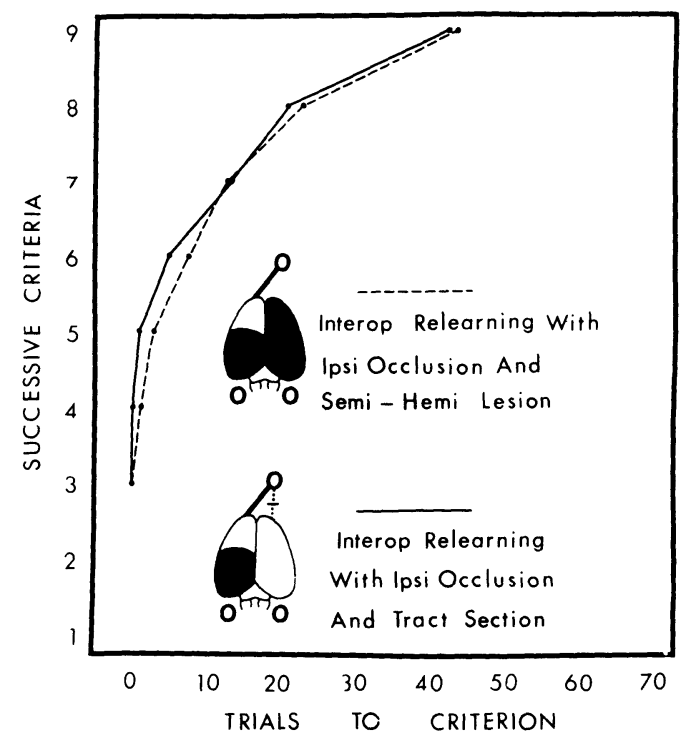

Figure 37. Solid: $\quad N=14, \quad R_{1}=42.0 \pm 6.68$ Dashed: $\quad N=13, \quad R_{1}=43.5 \pm 7.37$

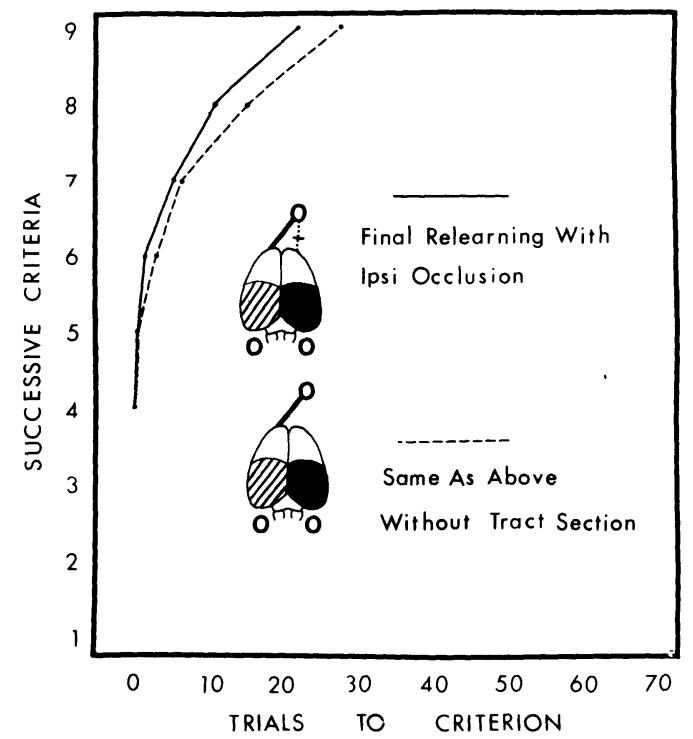

Figure 38. Solid: $\quad N=14, \quad R_{1}=23.0 \pm 4.54$

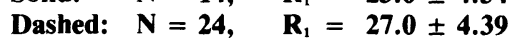

the animals would re-relearn the habit $\left(R_{2}\right)$ in approximately 27 trials. The outcome, as measured in a study of Lee, was that the mean score for ultimate retention was approximately 23 trials (Figure 38 ). Hence, we concluded that the theory of suppression was almost certainly correct, for we saw no other way of accounting for the fact that removal of a denervated posterior quadrant could produce an impairment of ultimate retention that was more than twice the minimal impairment that is noted when an innervated cortical quadrant is destroyed.

\section{FORGETTING AS A FACTOR IN IMPAIRMENTS OF ULTIMATE RETENTION}

We next consider findings which have served to erode the bases of the theory of suppression in that they have questioned one of the assumptions of the studies of Glendenning, Ritchie, and Lee. The critical assumption was that animals prepared with unilateral posterior lesions would not, if retrained while monocularly occluded, exhibit impairments of ultimate retention unless and until they were subjected to second-stage ablations. That is, we presumed that over 12 days' time, a retrained unilateral posterior subject would not exhibit forgetting of the habit if given re-retraining for an $R_{2}$ test without having been reoperated.

We had, of course, considered the possibility, and had put it to a number of tests. Glendenning (1972), for example, trained 14 normal animals, subjected them to one-stage bilateral posterior extirpations, retrained them on the habit, and then retested them for ultimate retention at the time that his two-stage bilateral posterior subjects were receiving the same tests. He found that these animals, all of which were given binocular retraining on the habit, re-relearned the habit in a mean/median of $1.0 / 0.5$ spaced trials. Hence, he concluded that if cortical suppression is removed before a rat has been retrained, the neural mechanisms for performance which develop as a function of additional training on the habit are then very stable over time.

However, in a study by Ritchie and Kirvel, we found that if one-stage bilateral posterior preparations are retrained with one eye, they not only are slower to relearn the habit than unoccluded subjects with similar ablations, but also show extremely poor postoperative retention of the habit. Thus, when the subjects were given second tests for ultimate retention of the habit, the animals required $20 \pm 3.6$ mean spaced trials to re-reach the $9 / 10$ criterion (Figure 39).

The value thus obtained was within a few trials of the re-relearning scores of Ritchie's two-stage visual preparations (Figure 40). Hence it could be argued that the second-stage deficits that Ritchie had observed had been due to forgetting plus the minimal 


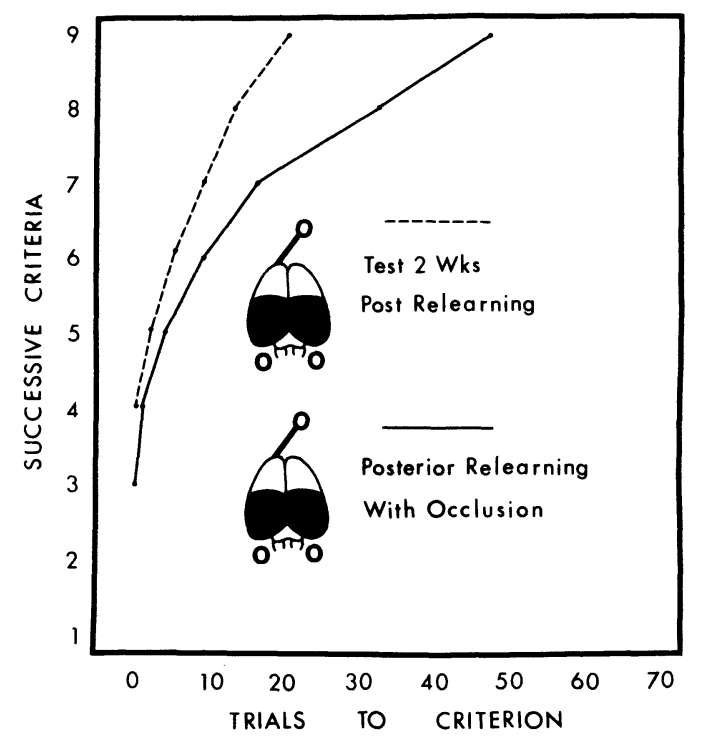

Figure 39. Solid: $\quad \mathbf{N}=13, \quad \mathbf{R}_{1}=47.0 \pm 8.04$ Dashed: $\quad N=13, \quad R_{2}=20.0 \pm 3.61$

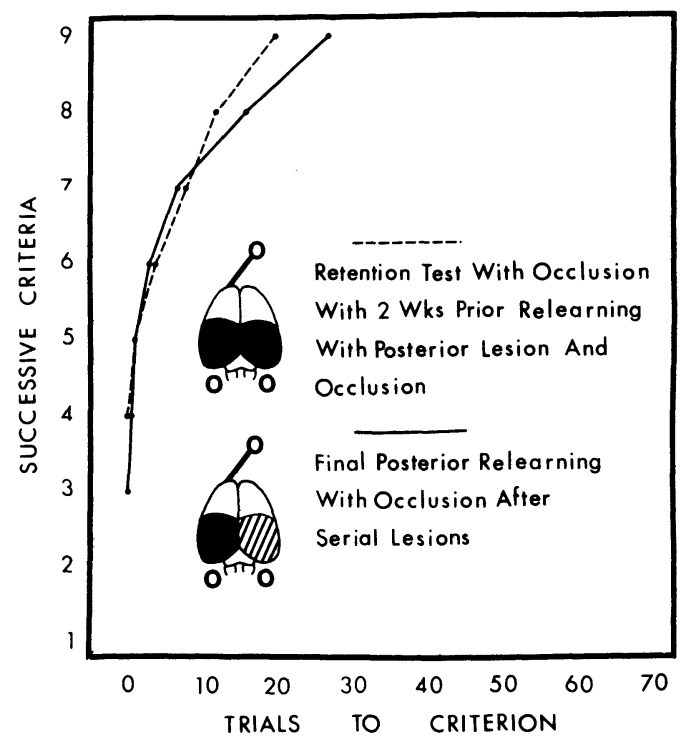

Figure 40. Solid: $\quad N=24, \quad R_{2}=27.0 \pm 4.39$ Dashed: $\quad N=13, \quad R_{2}=20.0 \pm 3.61$

effect that is always obtained upon removal of a quadrant of the cortex. It also could be argued that the $R_{2}$ impairments of the two-stage posterior preparations that Glendenning retrained with occlusion between the operations resulted from the same two factors. Indeed, the only problem with such a proposal was the fact that Glendenning had also observed that two-stage posterior preparations which are given binocular retraining during $R_{1}$ tests have $\mathbf{R}_{\mathbf{2}}$ losses which are similar to those of subjects which are given interoperative monocular retraining (cf. Figure 16).
Notably, however, the latter animals had rerelearned the habit $\left(R_{2}\right)$ in approximately 13 mean trials. Although that score was only 3 trials lower than the $\mathbf{R}_{\mathbf{2}}$ scores for the subjects that had previously received interoperative monocular retraining on the habit, it also was only 3 trials higher than the 10 which seemed to be the minimum for subjects prepared with unilateral posterior lesions. Accordingly, with hindsight, we found it very easy to see that the control had been imperfect, and hence that it was possible that $\mathbf{R}_{\mathbf{2}}$ scores are critically dependent upon the type of $R_{1}$ retraining.

From these considerations, it was clear that we needed to assess the consequences of monocular occlusion for long-term retention of the habit by subjects prepared with unilateral posterior ablations. We did so in studies which were carried out by Lee. First she confirmed the findings of Glendenning and of Ritchie that monocularly occluded unilateral posterior preparations relearn the habit either quickly or slowly as a function of the side of the occlusion. Her $R_{1}$ score for a group that was retrained with the eye contralateral to the lesion was 30 spaced trials. Her $R_{1}$ score for a group that was retrained with the eye ipsilateral to the lesion was 11 spaced trials. These scores corresponded very closely to the scores obtained by Ritchie and Glendenning, which, when combined, were 28 trials for contralateral subjects and 11 trials for ipsilateral subjects.

Next, Lee waited for about 2 weeks, and then retrained the preparations. She found that the subjects which had relearned the habit in 11 mean spaced trials re-relearned the habit in 4 trials (Figure 41). She found that the subjects which had relearned the

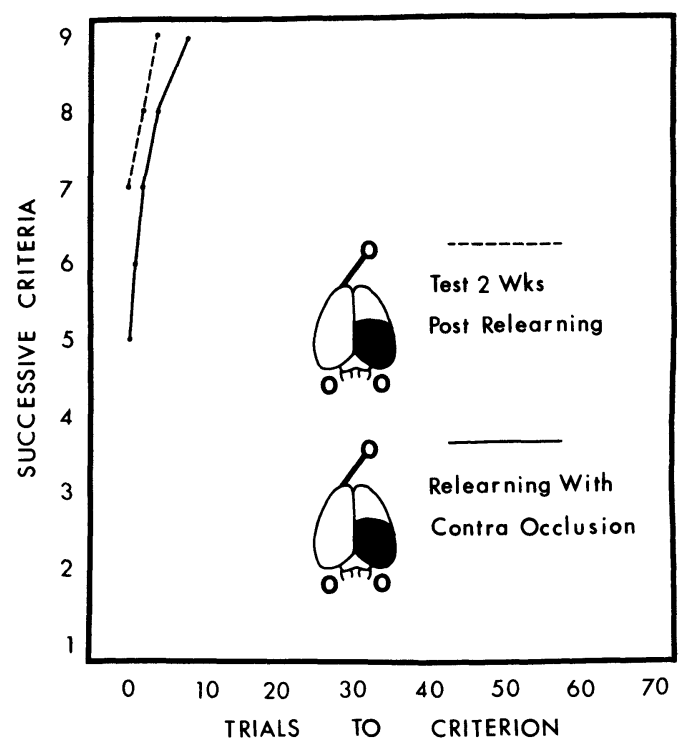

Figure 41. Solid: $\quad \mathbf{N}=11, \quad \mathbf{R}_{1}=8.2 \pm 2.08$ Dashed: $\quad \mathbf{N}=11, \quad \mathbf{R}_{2}=3.9 \pm 1.12$ 
habit in 30 mean spaced trials re-relearned the habit in 14 (Figure 42). Hence it was apparent that when animals are trained with the eye contralateral to a unilateral posterior lesion, they not only relearn the habit very slowly but they also forget it very quickly.

The findings of Ritchie and Kirvel and of Lee posed the following problems for the theory of cortical suppression. The result that had prompted the statement of the theory was that $R_{2}$ scores for serial posterior subjects had been found to be the same regardless of the $R_{1}$ levels of performance of the subjects. However, one could think from the new observations that the symmetries had been coincidental. Thus one could argue that animals prepared with contralateral first-stage posterior ablations would re-relearn the habit after second-stage ablations in the minimum of 10 trials were it not for the fact that they also forget what they learn during $R_{1}$ retraining. Also one could argue that conversely treated subjects, although they retain the habit that they learn when given interoperative training $\left(R_{1}\right)$, take many trials to re-relearn the habit $\left(R_{2}\right)$ because of the fact that their second-stage ablations destroy the visual cortex that is opposite the unoccluded eye.

It was also apparent that the findings compromised the support for the theory of suppression that had been obtained in the denervation study. Thus Lee had found that animals prepared with first-stage ablations of the ipsilateral tract and the contralateral posterior cortex re-relearn the habit after second-stage ablations of the denervated posterior cortex in 23 mean trials. But the outcome of the study of Ritchie and Kirvel had shown that simultaneous bilateral preparations, if retrained with monocular occlusion after surgery, require 20 mean trials to re-relearn the habit after having first relearned the habit. Hence, one could argue that the first-stage procedure in the denervation study had effectively destroyed the functions of the posterior cortex, that the animals had relearned the habit but had then forgotten, and therefore that the secondstage ablations of the denervated cortex had had no detectable effects upon ultimate retention of the habit.

It thus became important that we closely reexamine the finding that led us to believe that habits which are relearned with one eye are virtually as stable as habits which are relearned with both eyes. The finding in question was Glendenning's (1972) observations that two-stage posterior preparations which were given interoperative binocular retraining had $\mathbf{R}_{\mathbf{2}}$ scores that were within $\mathbf{3}$ trials of the $\mathbf{R}_{\mathbf{2}}$ scores of two-stage subjects which were given interoperative monocular retraining on the habit. What we needed to know was whether that score of 13 trials had been spuriously higher than 10 mean trials or spuriously

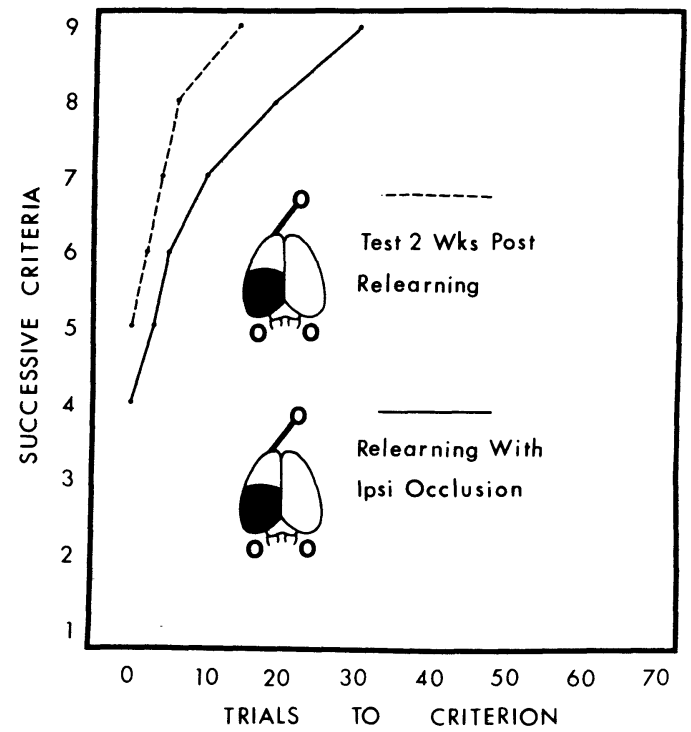

Figure 42. Solid: $\quad N=10, \quad R_{1}=30.0 \pm 5.06$ Dashed: $\quad N=10, \quad R_{2}=14.0 \pm 3.79$

lower than 16. Thus, if the score had been spuriously low, as Glendenning had interpreted it to be, its upward revision would suggest that forgetting is a function of whether the $R_{2}$ tests are conducted with monocular occlusion. Alternatively, if the score had been too high, its downward revision would suggest that a partial visual lesion will not, in fact, result in an incomplete release of suppression.

To settle the question, Lee trained a group of 14 rats, subjected them to unilateral lesions of the posterior cortex, retrained them with both eyes open to criterion $\left(R_{1}\right)$, overtrained them until they each had had a total of 41 interoperative training trials, subjected them to second-stage ablations of the stillremaining contralateral posterior cortex, and retested them for ultimate retention of the habit with both eyes. For this group of animals, the $R_{1}$ score was 8.3 mean spaced trials, or within a trial or so of expectations from the findings of Glendenning. However, the score for ultimate retention was 7.4 mean spaced trials (Figure 43). Because the latter mean was close to the minimal number of trials that is required for relearning after any lesion of a cerebral quadrant, the outcome was disastrous for the concept of partial release. Thus it indicated that a partial visual lesion induces a condition such that practice will then yield a maximal protection of ultimate retention of the black-white habit.

\section{EFFECTS UPON RETENTION OF CORTICO-TECTAL ABLATIONS}

We next consider studies by Ritchie and Kirvel of retention of the habit by subjects prepared with tectal ablations or cortico-tectal ablations. This facet 


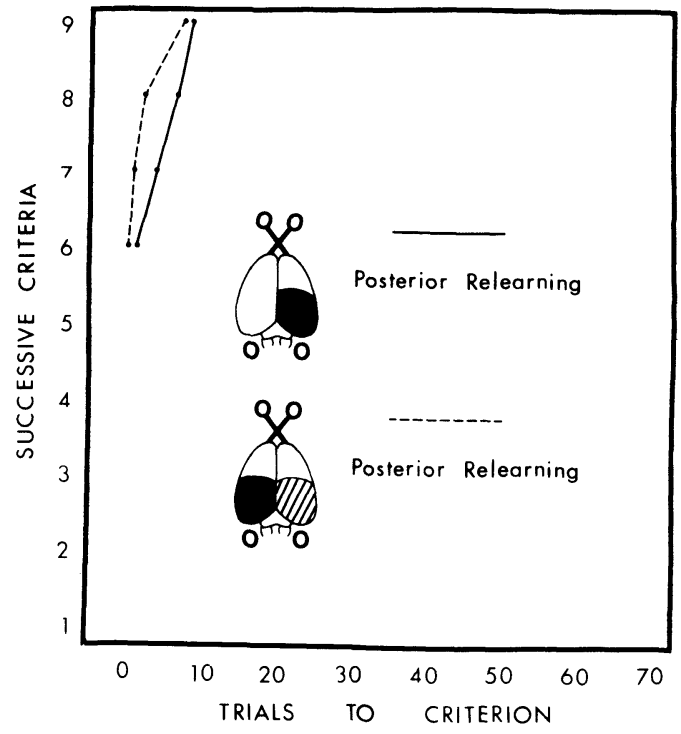

Figure 43. Solid: $\quad N=14, \quad R_{1}=8.3 \pm 1.16$ Dashed: $\quad N=14, \quad R_{2}=7.4 \pm 2.46$

of the program was instigated by experiments with cats which were carried out by Sprague (1966) and Sprague and Meikle (1965). The finding that attracted our attention, and which we shall describe as Sprague's effect, was first observed in cats prepared with unilateral posterior lesions and lesions of either the ipsilateral or the contralateral midbrain tectum.

The studies of Sprague and of Sprague and Meikle showed that cortical ablations or tectal ablations are followed by reduced reactions by the subjects to small visual targets when the targets are presented in the contralateral visual field. They also established that this sensory neglect is enhanced if the cortical ablation is combined with an ipsilateral unilateral tectal ablation. However, they found that a lesion of the tectum, if placed contralateral to the lesion of the posterior cortex, results in a dramatic restoration of responses to targets presented in the field contralateral to the side of the cortical ablation.

As our first venture, we asked if that result could also be obtained with hooded rats. We found that it could in an investigation of Kirvel, Greenfield, and Meyer (1974). In the further studies described in this report, we were principally concerned with the question of whether the Sprague effect could also be detected through assessments of rates of postoperative relearning of the black-white discrimination habit. We thought that if crossed collicular ablations could facilitate relearning of the habit by subjects with unilateral posterior lesions, the result might imply a restoration of useful spatial vision to the field contralateral to the cortical ablation.

The tectal ablations were extensive and deep, and were comparable in scope to those which are described by Kirvel (1975) and by Kirvel et al. (1974). As we noted earlier, we found it necessary to increase the recovery times for tectal subjects from 11 to 21 days. We chose that interval because we observed that it takes unilateral tectal preparations about 3 weeks to exhibit a recovery from their strong initial tendencies to turn to the ipsiversive side.

We found that, after 3 weeks, unilateral tectal subjects can be trained in the Thompson-Bryant test situation. They then relearn the black-white habit in approximately 10 spaced trials. We also observed that preparations of this kind, if retrained with monocular occlusion, will relearn the habit in about 10 trials regardless of which eye is occluded (Figure 44).

We also found that if unilateral tectal ablations are combined with simultaneous ipsilateral or contralateral posterior cortical ablations, the rate of relearning of the black-white habit is the same provided that the habit is relearned with the eye ipsilateral to the posterior cortical ablation (Figure 45). For these two conditions, we observed that the scores are higher than they are for unilateral posterior preparations that are similarly retrained, but also that the scores are close to the sums of the relearning scores for unilateral tectal and unilateral posterior subjects.

We found that when the same combinations are employed, but the subjects are retrained with the eye contralateral to the posterior cortical ablation, a tectal ablation that is ipsilateral to the cortical ablation enormously potentiates the black-white relearning deficit (Figure 46). This was as expected from the findings of Sprague (1966) and Sprague and Meikle (1965) with respect to crossed visual

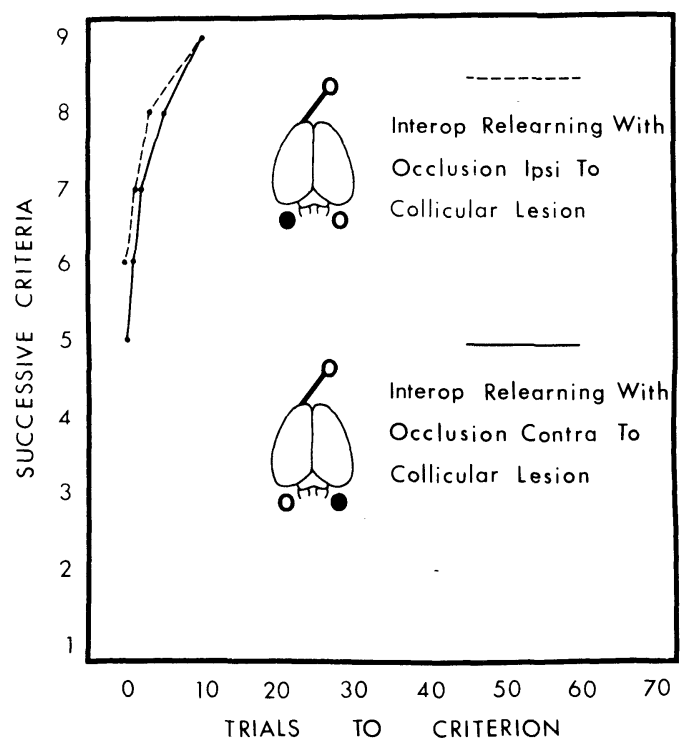

Figure 44. Solid: $\quad N=9, \quad R_{1}=10.0 \pm 3.00$ Dashed: $\quad \mathbf{N}=9, \quad \mathbf{R}_{1}=10.0 \pm 3.00$ 


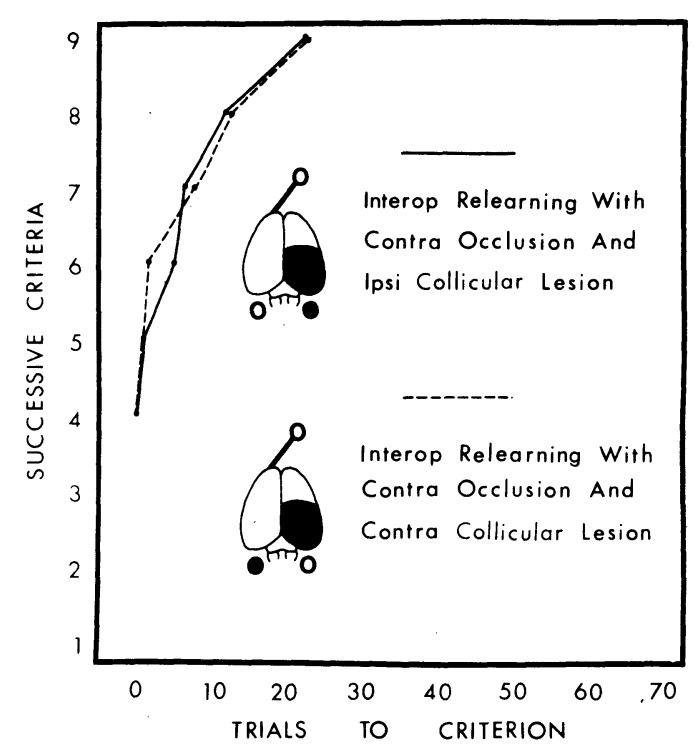

Figure 45. Solid: $\quad \mathbf{N}=17, \quad \mathbf{R}_{1}=20.9 \pm 5.32$ Dashed: $\quad N=14, \quad R_{1}=23.8 \pm 2.49$

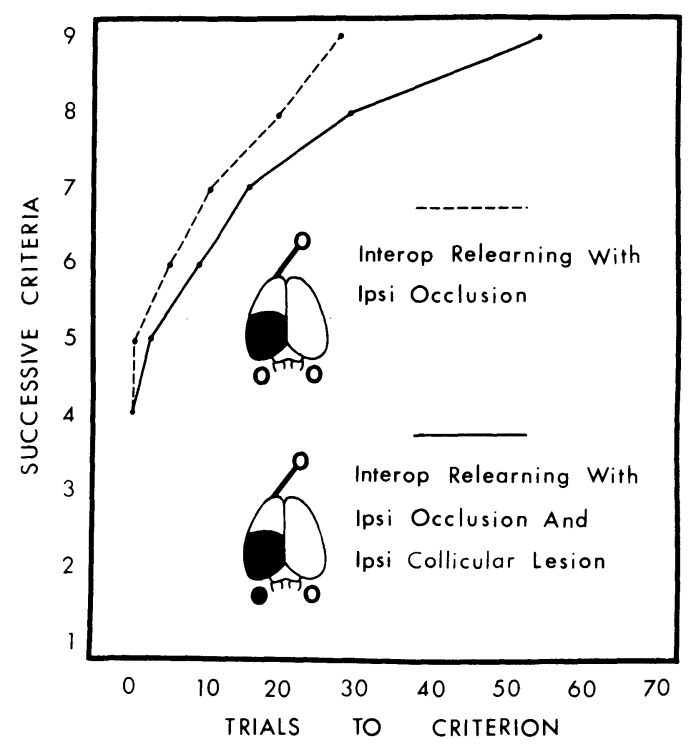

Figure 46. Solid: $\quad N=12, \quad R_{1}=54.2 \pm 4.71$ Dashed: $\quad N=44, \quad R_{1}=28.0 \pm 2.40$

neglects, although it must be stressed that monocular occlusion does not restrict the visual input to the brain's damaged side.

We found that crossed cortico-tectal extirpations have lesser effects upon retention of the habit than comparable but homolateral lesions when the rats are retrained with the eye contralateral to the posterior cortical ablation (Figure 47). However, there was no indication in the data that a contralateral tectal ablation improves the performances of unilateral posterior subjects that are retrained on the habit with the eye contralateral to the cortical ablation (Figure 48). The latter comparison was some- what imperfect because the recovery times were different for the two groups of subjects, and perhaps a further study would show that the crossed-lesioned group's inferiority was due to additional forgetting of the habit during the 10 extra days that they rested after surgery. However, the more important point was that their levels of performance of the blackwhite habit had not been dramatically improved by a lesion that unquestionably improves a cat's or rat's responsiveness to perimetric targets presented in the field contralateral to a cortical ablation.

We next operated the latter group of subjects for second-stage removals of their still-intact posterior cerebral quadrants. The animals were then permitted

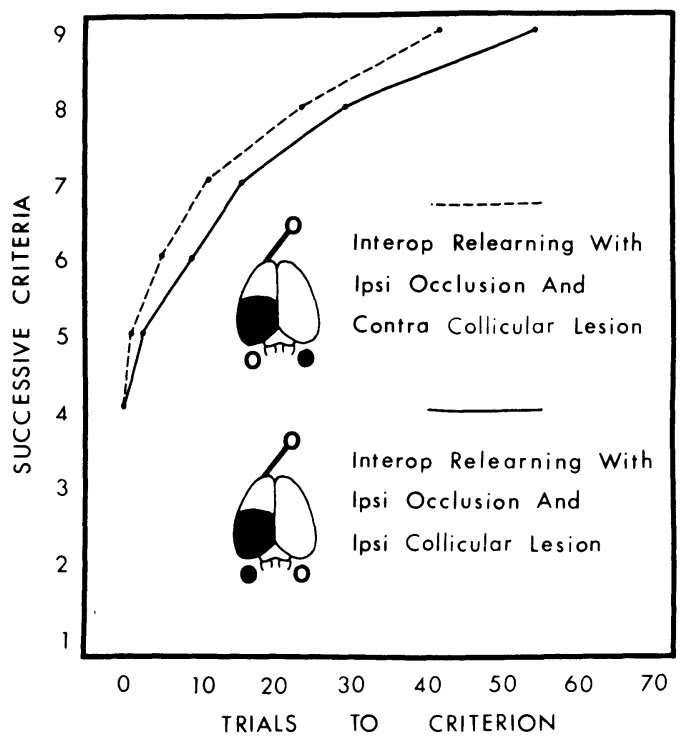

Figure 47. Solid: $\quad N=12, \quad R_{1}=54.2 \pm 4.71$ Dashed: $\quad N=17, \quad R_{1}=40.0 \pm 4.37$

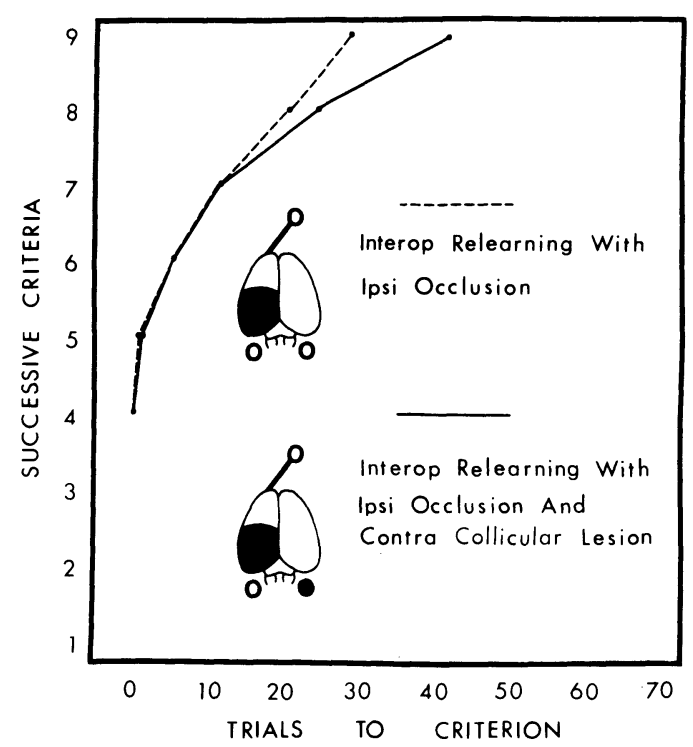

Figure 48. Solid: $N=17, \quad R_{1}=40.0 \pm 4.37$ Dashed: $\quad \mathbf{N}=44, \quad \mathbf{R}_{1}=28.0 \pm 2.40$ 
to recover from the surgery for 11 days, and then were once again retested for retention of the habit. We found that when the second-stage ablations destroyed the quadrant that had not received a crossed visual input, there was only a modest effect upon relearning of a chronic lesion of the tectum (Figure 49). Moreover, under those conditions of retraining, we found that retention of the habit was not differentially affected as a function of the side of the tectal ablation (Figure 50).

We found that when the second-stage ablations destroyed the posterior quadrant that was contralateral to the open eye, the effects upon retention were reminiscent of the outcomes obtained when that component of the cortex is destroyed by a first-stage cortico-tectal extirpation. The rate of relearning was substantially retarded, and that was so regardless of the side of the first-stage unilateral tectal ablation (Figure 51). Hence, once again, we were unable to observe facilitation of relearning of the habit by a crossed unilateral ablation of the midbrain tectum. Indeed, in the second-stage comparisons, the rate of relearning was somewhat slower for the crossed than for the uncrossed subjects, and that result was just exactly opposite to what we had expected to observe.

\section{THE STRUCTURAL BASES OF RECOVERIES OF THE BLACK-WHITE HABIT}

Our final group of findings have to do with the question of what central structures mediate postoperative recoveries of the black-white habit. First, we will say that we have found no procedure which will block relearning of the black-white habit in the same sense that radical posterior extirpations will

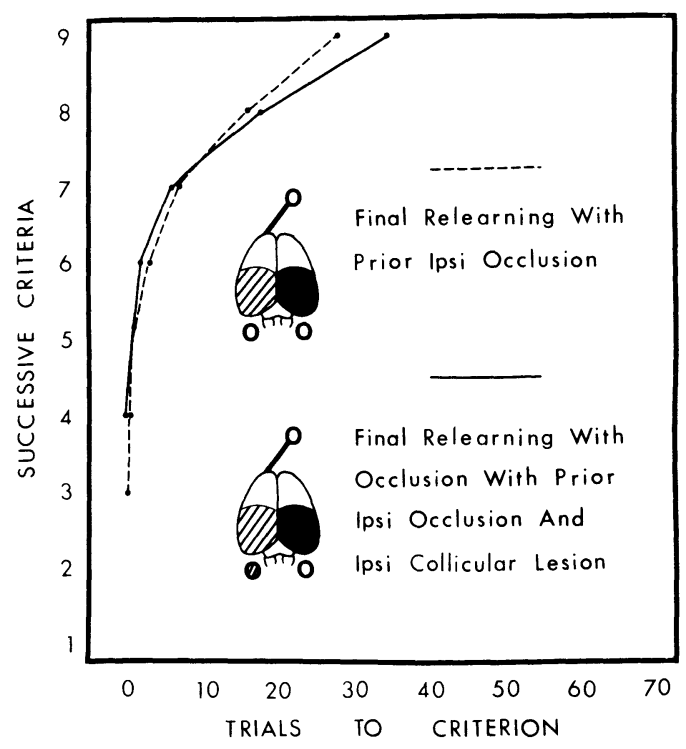

Figure 49. Solid: $\quad N=12, \quad R_{2}=35.0 \pm 6.06$

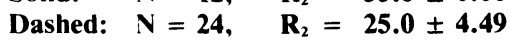

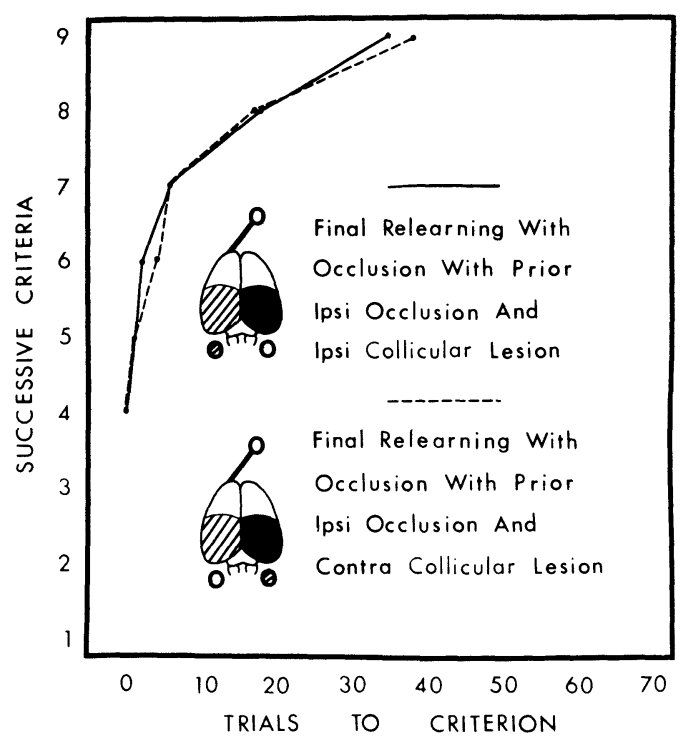

Figure 50. Solid: $\quad N=12, \quad R_{2}=35.0 \pm 6.06$ Dashed: $\quad N=17, \quad R_{2}=40.0 \pm 9.46$

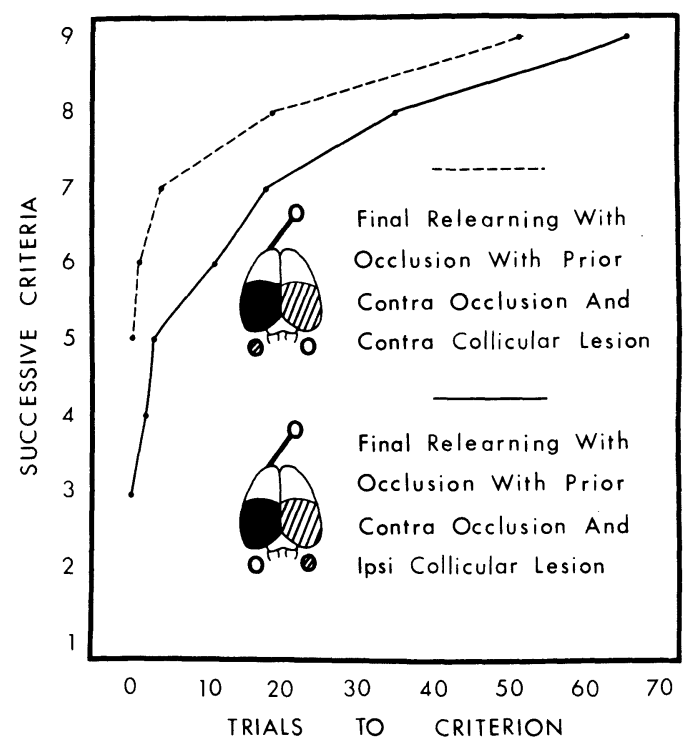

Figure 51. Solid: $\quad N=17, \quad \mathbf{R}_{2}=65.9 \pm 9.11$ Dashed: $\quad N=14, \quad R_{2}=51.6 \pm 5.49$

block postoperative relearning of a pattern habit. Hence our information with respect to the question concerns those substrates which are evidently not essential for recovery to occur.

From the outcomes described in the preceding sections, we can say with assurance that the dorsolateral cortex, despite its crucial role in performance of the habit by animals whose brains are intact, is evidently dispensable although its destruction retards both learning and relearning. We have not yet examined other cerebral components except for the amygdala and septum, whose destructions we have 
found to have but very small effects upon postoperative retention.

However, there is one important qualification with respect to the effects of ablations of the forebrain septum. After we discovered that amphetamine treatments facilitate relearning of the habit by subjects with radical posterior ablations, we asked if that effect could also be produced as a consequence of septal release (Brady \& Nauta, 1953). What we found, instead, in a study of the question by Meyer et al. (1968), was that animals prepared with simultaneous ablations of the posterior cortex and the forebrain septum could hardly be distinguished from animals prepared with complete dorsal pallial ablations (Figure 52). In contrast, bilateral anterior preparations, if also prepared with septal lesions, have no greater deficits than those which were produced by the anterior cortical ablations (Figure 53). Hence we have concluded that the septum is one of the components of an anterior system that is functionally distinct from the systems related to the posterior quadrants of the cortex.

In the rest of our studies with respect to the substrates of recoveries of the black-white habit, we mainly have been concerned with the identification of the visual pathways which mediate postoperative relearning. In general, our approach has been to train normal subjects on the habit, to prepare them with first-stage bilateral posterior ablations, to retrain them $\left(R_{1}\right)$, and then to prepare them with second-stage ablations of other visual structures. All of these experiments have been conducted with binocular retraining on the habit, and hence we believe that the second-stage effects were not contaminated by interoperative forgetting.

The first of these experiments concerned the effects of second-stage bilateral ablations of the midbrain

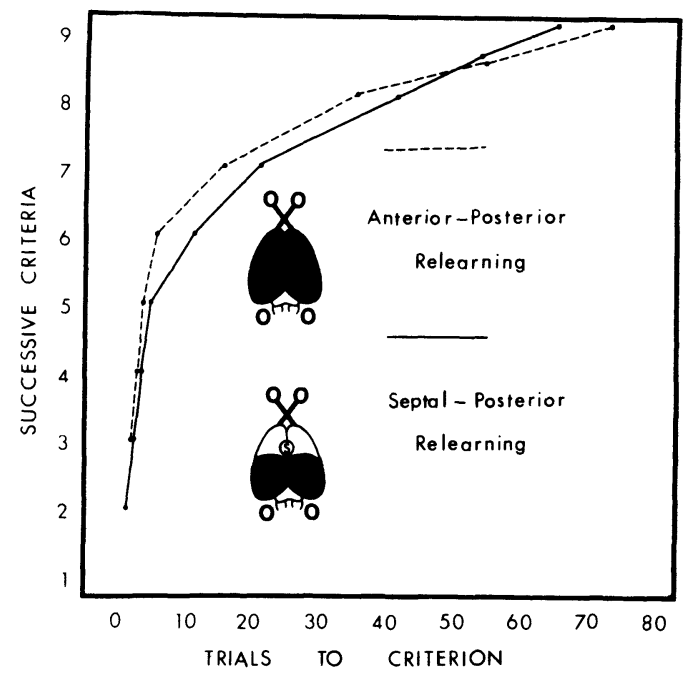

Figure 52. Solid: $\quad \mathbf{N}=27, \quad \mathbf{R}_{1}=66.1 \pm 7.50$ Dashed: $\quad N=30, \quad R_{1}=74.0 \pm 9.30$

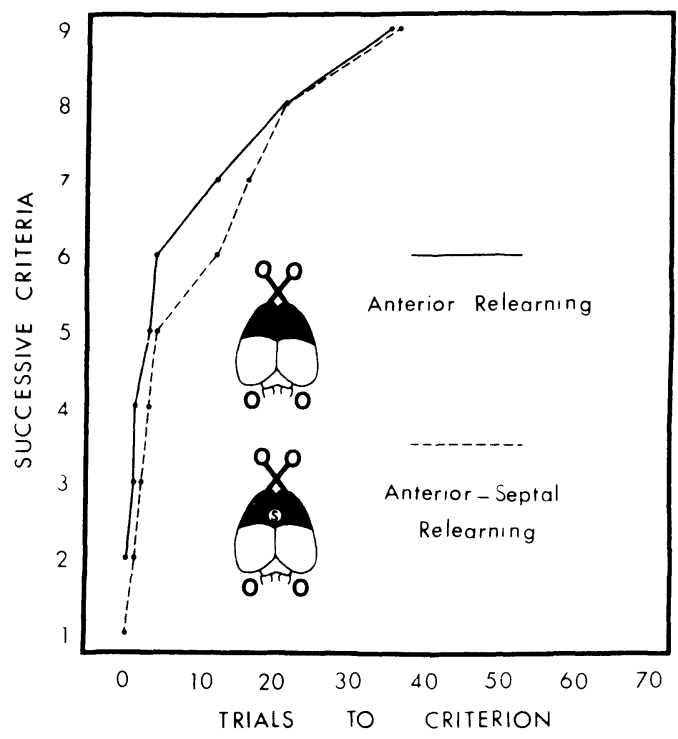

Figure 53. Solid: $\quad N=47, \quad R_{1}=33.7 \pm 3.87$ Dashed: $\quad N=15, \quad R_{1}=36.0 \pm 7.20$

tectum. We found that the second-stage tectal ablations had approximately the same effects upon rerelearning $\left(\mathbf{R}_{\mathbf{2}}\right)$ as the first-stage bilateral posterior ablations had upon relearning of the habit (Figure 54). The second-stage effect was much less pronounced than expected from the findings of Norton and Clark (1963) with respect to the effects upon retention of a brightness habit by cats prepared with one-stage cortico-collicular ablations. Hence, we suspect that the interoperative practive that we gave our subjects conveyed some protection of ultimate retention of the habit. However, in agreement with the findings of Fischman and Meikle (1965) and Urbaitis and Meikle (1968) for cats, it was plain from the study that the black-white habit can be performed by subjects that have been deprived of both of the principa! components of the visual system.

Pathways through the ventral LGNs, which survive bilateral posterior ablations, were given likely roles as mediators of recovery of the habit when Goodman and Horel (1966) observed that the nuclei are structures that receive terminals which sprout from the fibers of the visual pathways when the posterior cortex is destroyed. The finding prompted Horel (1968) to use the successive-ablation procedure to examine the effects of second-stage lesions of the ventral LGNs upon ultimate retention of the habit in subjects which had earlier been prepared with bilateral posterior ablations and had then been retrained on the habit. Horel observed that the second-stage lesions reinstated the losses of retention which were seen following the first-stage ablations. However, he also observed that his subjects were capable of re-relearning $\left(\mathbf{R}_{\mathbf{2}}\right)$, and hence it was apparent that the rats had retained a competence for mastery of the problem. 


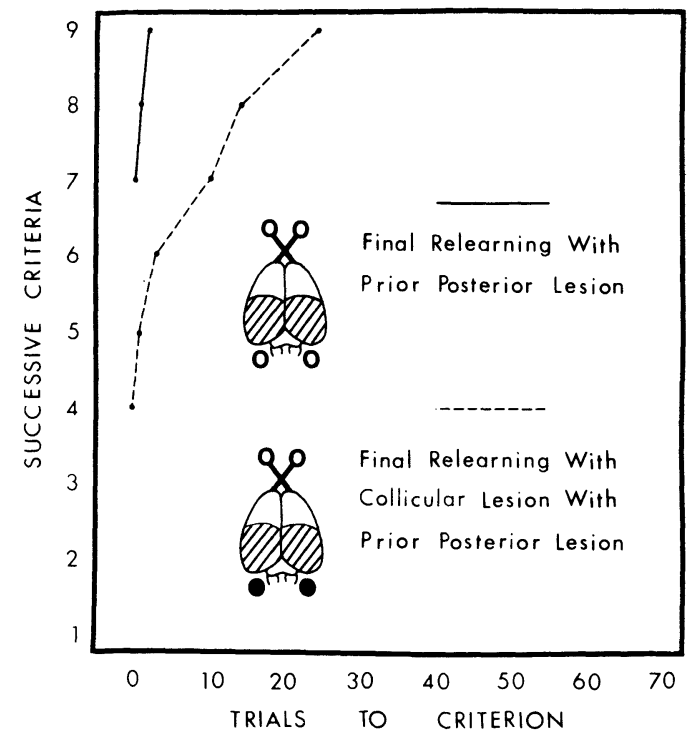

Figure 54. Solid: $\quad N=14, \quad R_{2}=2.1 \pm 0.71$ Dashed: $\quad N=9, \quad R_{1}=24.0 \pm 6.00$

Goodman and Horel (1966) also observed that sprouting terminals of optic-tract neurons enter the pretectal region when the posterior cortex is destroyed. That finding prompted Horel (1968) to examine the effects of second-stage pretectal ablations upon retention of the habit by subjects that had previously relearned the habit after they had been prepared with first-stage posterior ablations. Horel found that second-stage pretectal ablations served to reinstate the deficit, but also that subjects thus prepared were able to re-relearn the habit in a mean of 69 massed trials.

In experiments with monkeys, Pasik and Pasik (1973) have found that relearning of a black-white habit is impossible provided that the cortex is destroyed and the subjects are also prepared with ablations of the accessory optic system. Lee has attempted to perform the same experiment with rats, but has not been completely successful. However, she has found that partial lesions of the system which by themselves have miniscule effects upon postoperative retention of the habit will greatly potentiate the deficits produced by lesions of the posterior cortex. Hence it appears that the accessory system is involved in recoveries of the habit, but as yet we are not in a position to say that its integrity is absolutely crucial.

In summary, then, recoveries of performance of the habit can occur after subjects with posterior lesions have also been prepared with ablations of most of the subcortical components of the posterior visual mechanisms. Second-stage ablations of the latter mechanisms will often yield impairments of ultimate retention which are no less severe than the effects of a cortical ablation, and that is most particularly true of ablations of pretectal/tectal mecha- nisms. Hence, we suspect that reinstatements of the habit are mediated via pathways related to that region, but their specification must await the results of further studies of the problem.

\section{SYNOPSIS}

Next, we present a synopsis of the principal empirical results of the program.

(A) Effects of simultaneous radical bilateral posterior cortical ablations:

(1) The preferences of normal rats for going to the black door in the black-white training situation are no longer observed.

(2) If the effect described above is discounted, the subjects learn the black-white habit at a much slower rate than unoperated rats learn the habit.

(3) The subjects, unless they are treated with amphetamine, will show no retention of a black-white habit that was learned before the surgery was performed.

(4) The foregoing finding that rates of learning and relearning are the same in untreated posterior subjects is independent of the level of preoperative training.

(5) The subjects will fail to exhibit acquisition or retention of a visual-form discrimination habit if the only available cues are differences between the orientations of lines.

(B) Effects of simultaneous radical bilateral anterior cortical ablations:

(1) The subjects have severe but transitory hypophagias which are lessened if the tissue in the lateral margins of the region are not encroached upon.

(2) The subjects still exhibit the normal rat's preference for responding to the black door when trained on the black-white discrimination habit.

(3) If their black-door preference is discounted, the subjects learn the black-white habit at the same rate as subjects with bilateral posterior ablations.

(4) The subjects' impairments with respect to learning are not simply due to inanition, for they also are observable in preparations with very long postoperative recoveries.

(5) The subjects relearn the habit after surgery at a faster rate than animals prepared with lesions of the posterior cortex.

(6) The subjects nonetheless have impairments of retention of the black-white habit as measured by comparisons with relearning rates for unoperated animals.

(C) Effects of combined bilateral ablations of the anterior and the posterior cortex:

(1) If both ablations are performed in one stage, the effect upon black-white relearning is greater than 
that which is produced by posterior ablations alone.

(2) If both of the ablations are performed in one stage, the effect upon relearning is close to the sum of the effects of each of the ablations.

(3) If the two ablations are successively combined and the subject is trained on the habit after having first sustained an anterior ablation, the effect upon relearning of a second-stage posterior ablation is the same as the effect of an equivalent first-stage ablation.

(4) The same thing is true if the two ablations are combined in the opposite order, for a secondstage bilateral anterior ablation has the same effect upon relearning of the habit as a first-stage bilateral anterior ablation provided that subjects with prior posterior lesions receive interoperative training.

(5) The effects of simultaneous anteriorposterior ablations upon relearning of the black-white habit are mimicked by combinations of septal and posterior ablations.

(6) However, ablations of the forebrain septum by itself have substantially smaller effects upon retention of the habit than do bilateral anterior ablations.

(D) Effects of two-stage bilateral removals of the posterior cortex:

(1) The effect upon ultimate retention of a visual CAR is less than the effect of a one-stage ablation provided that the subjects are kept in the light or are subjected to strong nonspecific stimulation between the two operations.

(2) The effect upon ultimate retention of the black-white habit is the same as that which is produced by a comparable one-stage bilateral posterior ablation.

(3) The foregoing finding is unaffected by light or dark housing or amphetamine treatments during the interoperative interval.

(4) However, interoperative training on the habit conveys protection of retention of the habit following the second-stage posterior ablation.

(5) The amount of protection of ultimate retention of the habit which results from interoperative training is not enhanced by interoperative overtraining.

(6) If interoperative training is given, the effect upon ultimate retention of the habit of the second-stage ablation is the minimal effect of an ablation of a cortical quadrant.

(E) Effects of monocular occlusion in conjunction with posterior cortical ablations:

(1) A unilateral posterior subject, if retrained with occlusion of the crossed visual input to the damaged cerebral hemisphere, relearns the blackwhite habit very quickly.

(2) However, such a subject, if retrained with occlusion of the crossed visual input to the undamaged hemisphere, relearns the habit very slowly.

(3) If subjects thus prepared are retrained in either manner and are subsequently tested for ultimate retention of the habit following a secondstage posterior ablation, their scores are the same despite the differences between their interoperative relearning rates.

(4) The latter observation is not a function of whether the tests for ultimate retention are concluded with both eyes or one eye.

(5) However, if the tests for ultimate retention are conducted with monocular occlusion, the scores for both groups are higher than they are when the tests are conducted without monocular occlusion.

(6) Monocular occlusion also retards the rate of relearning of the habit by subjects prepared with simultaneous bilateral ablations of the posterior cortex.

(7) However, monocular occlusion is without effect upon initial acquisition or retention of the habit by normal animals.

(8) Subjects with unilateral posterior lesions, if retrained with occlusion of the crossed visual input to the undamaged cerebral hemisphere not only are very slow to relearn the habit, but also forget the habit quickly.

(9) The forgetting thus observed is sufficient to account for losses of retention of the habit which are seen when unilateral posterior subjects are prepared with a second-stage ablation of a previouslydenervated posterior cortical quadrant.

(F) Effects of monocular occlusion in conjunction with anterior cortical ablations:

(1) A unilateral anterior subject, if retrained with occlusion of the crossed visual input to the damaged hemisphere, rapidly relearns the blackwhite habit.

(2) A subject thus prepared, but retrained with occlusion of the crossed visual input to the undamaged hemisphere, is slower to relearn the habit.

(3) The different effects of occlusion are enhanced if unilateral anterior ablations are combined with ablations of other quadrants of the dorsolateral cortex.

(4) The enhancements thus produced are observed regardless of whether the combined ablations are performed in one stage or two stages.

(5) Monocular occlusion also lateralizes the effects of unilateral anterior ablations upon retention of visual form discrimination habits.

(6) If the test is for retention of a form discrimination, occlusion of the crossed visual input to the undamaged hemisphere has much the same effect regardless of whether the subject has a unilateral anterior lesion or a unilateral posterior lesion. 
(G) Effects of monocular occlusion in conjunction with corticotectal ablations:

(1) Unilateral midbrain tectal subjects, if tested for retention of the black-white habit while monocularly occluded, relearn the habit very quickly.

(2) They do so regardless of whether the occluder is worn on the eye ipsilateral to or the eye contralateral to the tectal ablation.

(3) If unilateral tectal ablations are combined with unilateral posterior cortical ablations, the effect upon retention is modest provided that the test is with occlusion of the crossed visual input to the damaged cerebral hemisphere.

(4) The result just described is independent of the side of the unilateral tectal ablation.

(5) However, if subjects with combined unilateral tectal and posterior cortical ablations are tested with occlusion of the crossed visual input to the undamaged cerebral hemisphere, their rates of relearning of the habit are tremendously retarded.

(6) The effect just described is not a consequential function of whether the unilateral tectal ablation is ipsilateral or contralateral to the unilateral cortical ablation.

(7) Also, the effect is not a consequential function of whether the combined ablations are performed in one stage or two stages.

(H) Effects of treatments with amphetamine:

(1) The treatments facilitate relearning of the black-white habit by subjects prepared with bilateral posterior ablations.

(2) The effect is obtained with doses of the drug that will not affect original learning of the habit by subjects prepared with bilateral posterior ablations.

(3) The treatments with amphetamine which serve to facilitate relearning of the habit by posterior preparations have no demonstrable effects upon the deficits produced by anterior ablations.

(4) The rate of relearning of the habit by treated bilateral posterior preparations is approximately the same as the rate of relearning by treated or untreated bilateral anterior preparations.

(5) The treatments, if given to subjects with unilateral lesions of the posterior cortex, will not induce protection of ultimate retention of the habit following a second-stage posterior ablation.

(6) The treatments, if given in doses which facilitate postoperative relearning of the black-white habit by subjects with bilateral posterior ablations, will not permit the subjects to relearn a visual-pattern problem.

\section{DISCUSSION}

Next, we shall discuss the findings of the program which seem to require some further comments. First, we were able to confirm, in principle, a number of the findings of Lashley. We find that remarkable in view of the fact that his earliest studies were concluded over 50 years ago, and with surgical and training procedures which were different from our own. We confirmed his conclusion that subjects with radical bilateral posterior ablations exhibit no postoperative retention of a preoperative learned brightness habit (Lashley, 1935). Also, we confirmed his conclusion that the loss of retention of the habit cannot be prevented by preoperative overtraining (Lashley, 1921a). And third, we confirmed his conclusion that relearning of the habit by posterior preparations occurs at a rate which, if measured in terms of trials and errors to a reasonably high criterion, is not very different from the rate at which the habit is initially acquired by normal subjects (Lashley, 1935).

However, we found that if animals are trained, as Lashley's were and ours were, to choose the lighter of a pair of cues, normal rats, but not rats with posterior lesions, will show a strong initial avoidance of the positive cue. But once they have overcome their handicap, normal rats learn the problem quickly, and their rates of learning are very much faster than the rates of learning or relearning of the habit by posteriorly decorticated subjects. The finding resolves the classical dilemma as to why an ablation of the posterior cortex should affect the retention of a habit that can be acquired just as readily without the cerebral cortex as with it.

That posterior subjects have substantial impairments of initial learning of the habit is particularly clear from comparisons between their performances and those of normal animals when training on the habit is continued to much more stringent criteria of performance than the ones we employed. The initial-learning curves of Horel et al. (1966) for normal and posterior subjects suggested that the functions, after having come together at approximately the $9 / 10$ criterion, would cross and then become progressively divergent as a function of additional practice. Spear and Braun (1969) have since examined that suggestion, and they found that the functions behaved exactly as expected.

Empirically, our most important difference from Lashley concerns his conclusion that anterior ablations are virtually without effect upon postoperative retention of the brightness habit (Lashley, 1921b). Although the effects of bilateral anterior ablations upon retention of the habit are smaller than those which are produced by posterior ablations of comparable extent, they nonetheless are real and persistent. Conceivably, the finding of Lashley was a function of his having overtrained his animals, for neither he nor we explicitly examined the question as to whether the deficits produced by anterior 
lesions are stable regardless of the level of preoperative training. We have not been able to discern another reason for the differences between the outcomes, and certainly the differences are not attributable to variations in the lesions. Thus, Lashley used a cautery in his surgeries, and his animals, although they showed excellent retention of the brightness discrimination habit, typically had lesions which involved cerebral cortex and also the corpus striatum.

We found that insofar as initial acquisition of the black-white habit is concerned, there is very little difference between the performances of subjects with bilateral anterior or posterior lesions (Horel et al., 1966). If the scores of such subjects are casually examined, they seem to present a paradox because the performances of anterior subjects are worse than those of posterior subjects. However, the difference is a function of the fact that anterior subjects are like normal subjects in that they avoid the white door, and the difference disappears when the effects of the bias are discounted. Hence our results are consistent with the notion that the cortex, if present, is widely involved in the processes which form memorial substrates, but that some of the systems related to the cortex are then of more importance than others for performances of habits which depend upon the substrates.

In our studies of animals prepared with combinations of ablations of quadrants of the cortex, we found that the deficits could often be predicted from the sums of the effects of ablations of the individual quadrants (Ritchie; Ritchie \& Lee). We found that the rule was particularly striking when applied to the data for subjects prepared with homolateral and heterolateral two-quadrant lesions. The effects of such albations are the same despite the fact that homolateral lesions spare the intrahemispheric connections between remaining quadrants, while heterolateral lesions destroy those connections in addition to severing the transcallosal inputs to the stillintact components of the cortex. Hence it appears that lateral interactions between the anterior and the posterior cortex cannot be of any great importance for performance of the habit, for if they were, the deficits of heterolateral subjects should have been somewhat greater than the deficits of homolateral subjects.

We suspect that the visually specific deficits which anterior lesions bring about arise from destruction of the anterior polysensory system. The system has yet to be identified in rats, but we predict its existence as a homolog to the polysensory system that Thompson, Johnson, and Hoopes (1963) discovered in the cat through recordings of evoked potentials from the sigmoid cortex. In experiments with cats (Meyer, Dalby, Glendenning, Lauber, \& Meyer, 1973), we found that small ablations of the zones immediately posterior to the cruciate sulci result in impairments of retention of a brightness habit, and we think that those impairments were similar in kind to the deficits produced by anterior ablations in rats. Hence, we believe that if the rat's somatomotor cortex were explored with electrophysiological techniques, regions would be found in which visually evoked potentials could be readily detected. Also, we believe that the regions would respond to stimuli in both visual fields, but principally to stimuli presented in the contralateral field.

Our findings with respect to the effects of prior ablations of the anterior cortex upon the rate at which the habit is relearned by posterior preparations constitute a disproof of Pavlov's (1927) theory of recovery. Thus, although our studies of anterior subjects support his contention that the anterior cortex is normally involved in performance of visual habits, animals with lesions of the posterior cortex relearn the habit at the same rate regardless of whether the anterior cortex is intact or not (Horel et al., 1966). This conclusion is for two-stage serial preparations which are given interoperative practice and hence, before their second-stage posterior extirpations, have already recovered from the deficits produced by ablations of the anterior cortex.

We also observed that a preexisting lesion of the posterior cortex is without effect upon the rate at which the habit is relearned by anterior preparations (Horel et al., 1966). Again, the conclusion is for subjects which have previously recovered from their first-stage ablations. We thought, when we first designed the posterior-anterior serial decortication study, that a first-stage ablation of the posterior cortex would enhance the effect of a second-stage bilateral ablation of the anterior cortex. However, the prediction from the theory of vicariation was completely incorrect. Instead, and in keeping with the theory of stability of functions that LeVere (1975) has proposed, we obtained no evidence whatever of induction of changes in the properties of anterior systems as a consequence of posterior injuries.

Notably, however, Scheff, and his colleagues (Scheff \& Wright, 1977; Scheff, Wright, Morgan, \& Bowers, 1977) have suggested that at least some recoveries of the habit are functions of inductions of reorganizations of the functions of regions of the posterior cortex which lie adjacent to the strike and extra-striate cortex. Their findings were that thirdstage ablations of the regions, but not far-anterior ablations, result in renewed impairments of retention of the habit by subjects that have previously recovered from two-stage ablations of the striate and extra-striate cortex. Also, they observed that interoperative practice which, as we have shown in confirmation of Thompson (1960), induces protection of ultimate retention following a second-stage 
posterior ablation (Glendenning, 1972; Ritchie; Ritchie \& Lee; Lee), greatly enhances the probability that visually evoked potentials will appear in what they describe as the contiguous-to-visual cortex.

We have found both results to be intriguing. However, Hughes (1976) has shown that the areas in question, which are areas 7 in Krieg's (1946) scheme, receive projections from the nucleus lateralis posterior. Also, Hughes has shown that bilateral NLP ablations, although they have no detectable effect upon retention of the black-white habit if the striate cortex is intact, will serve to potentiate the modest consequences of lesions of the striate cortex for retention of the habit. Hence it appears that NLP system normally has visual functions, but functions which are difficult to demonstrate until the striate cortex is destroyed.

In light of Hughes' results, we think that Scheff et al. have shown that interoperative practice with the habit will enhance the importance of the NLP system in postoperative performance of the blackwhite habit by subjects prepared with geniculocortical ablations. However, inasmuch as the NLP system is one of the posterior visual systems, their findings offer no support for the concept that extravisual systems of the cortex can vicariously acquire visual functions. But their work is nonetheless of considerable value, for it shows how tenaciously a rat that still has a cortically related visual system will rely upon the system for performance of a habit that is learnable by subjects with complete dorsal pallial ablations (Meyer et al., 1968).

We believe that the cortically related systems are crucially involved in form perception. Thus we have observed that animals prepared with radical posterior ablations have no demonstrable capacity to learn the oblique-stripes discrimination problem (Horel et al., 1966; Jonason et al., 1970). We think that the problem is an excellent test of visual form perception because it is insoluble in terms of reactions to overall differences in flux, in terms of reactions to overall differences in contour, in terms of reactions to local differences in flux, in terms of reactions to local differences in contour, or in terms of reactions to quantitative cues that a subject might derive from a process of horizontal scanning (cf. Ritchie, Meyer, $\&$ Meyer, 1976). Accordingly, performance of the problem implies that the subject is able to perceive the orientations of contours, and we have never seen a sign of that capacity in rats with radical posterior ablations.

We must stress that this conclusion is for animals prepared with very large posterior ablations. Lashley (1939) believed that visual form perception was a function of the striate cortex, and he thought that the geniculocortical projections terminated within the striate cortex. However, Hughes (1976) has shown that striatal preparations can learn the oblique- stripes problem, and also that ablations of the striate cortex fail to yield the retrograde thalamic changes in the dorsal LGNs which are observed in rats prepared with radical posterior ablations. Hughes' results parallel the findings of Doty (1971) and of Sprague, Levy, DiBerardino, and Berlucchi (in press) for cats, and reconcile our concept with the finding of Dru, Walker, and Walker (1975) that rats prepared with two-stage subtotal ablations of the posterior cortex can relearn a problem that can be construed as a test of visual form perception.

A recent observation of Spear and Barbas (1975) poses more important difficulties. Thus, they have observed that if rats are prepared with serial posterior ablations and are also given interoperative practice with the horizontal-vertical stripes discrimination problem as a test of form perception, they are capable of reasonably rapid relearning of the problem following the second-stage posterior ablation. The result was for subjects whose ablations resulted in complete degenerations of the dorsal lateral geniculates and hence, in terms of classic concepts, for subjects with complete visual cortical ablations.

But we see two problems with the study. One is with the choice of the horizontal-vertical problem as the test of form perception, and the other is the fact that ablations which result in complete degenerations of the LGNds can spare two components of the posterior NLP system. That the latter mechanism is involved in form perception is clear from an experiment of Hughes (1976), who has shown that stereotaxic NLP ablations enhance the impairments of visual-pattern learning which are seen in rats prepared with bilateral ablations of area 17 of Krieg (1946). Hence, until the problems are resolved by further studies, and specifically with tests for oblique-stripes performances by rats prepared with radical ablations, we shall continue to be of the opinion that radical ablations, no matter how arrived at, will always produce complete and permanent impairments of visual form perception.

Although our conclusion could seem to be unduly pessimistic, we base it in part upon our past disappointments in our search for procedures which would serve to ameliorate impairments of visualpattern learning. We began treating rats with posterior ablations with low doses of amphetamine after we observed that the treatments would serve to reverse the visual placing deficits of cats with posterior ablations (Meyer et al., 1963). Thereafter, Braun (1966) showed that amphetamine treatments reinstate placing to visual surfaces by rats prepared with lesions of the entire dorsal pallial cortex, and also that rats with posterior ablations would place to visual cues regardless of whether they were treated with amphetamine or not. Hence, until we found that amphetamine treatments would not 
make it possible for posterior subjects to learn the oblique-stripes discrimination problem (Jonason et al., 1970), we were fairly well convinced that the posterior cortex was not as significant for visual form perception as many of our predecessors thought.

We undertook our studies of subjects prepared with cortico-collicular ablations for the same basic reason that we undertook our studies of the actions of amphetamine treatments. Thus, if we had found that a crossed tectal lesion facilitated relearning of the black-white discrimination habit, our next step would then have been to test the subjects for learning or relearning of our visual-form discrimination problem. However, our results for black-white habits offered no suggestion that useful pattern vision was restored by that procedure to the field contralateral to a unilateral posterior lesion. Instead, we observed that neither a successive nor a simultaneous tectal ablation resulted in a positive effect upon retention of the black-white discrimination habit. The successive observation contrasts with the findings of Wood (1975) in experiments with cats, who reported that crossed collicular ablations facilitate recoveries of the black-white habit if the tectal extirpations precede the unilateral ablations of the posterior cortex.

The negative effects of tectal ablations are among the most powerful of all of the effects that we have seen (Ritchie \& Kirvel). One of their most interesting characteristics is that they are just as readily detected in subjects with chronic collicular ablations as in subjects with short recovery times. Their second striking feature is that they are not a function of the nature of the visual input with which the habit is relearned. That is, the effects of monocular occlusion in subjects with cortico-collicular ablations appear to be determined almost completely by the open eye's relation to the lesion of the posterior cortex. We know of no theory of the visual mechanisms which will give a good account of such results, but we think that they are generally consistent with concepts which stress the importance of the vertical relationships between the components of the systems (Berlucchi, Sprague, Levy, \& DiBerardino, 1972; Smith, 1938).

We believed for a time, and we thought with good reason, that postoperative amnesias for the brightness habit are functions of the fact that the cortex, if present, limits the formation of extraisocortical systems for performance of the habit (Glendenning, 1972). The theory accounted for many observations, and it subsequently weathered two exceptionally demanding quantitative tests of its predictions. However, the logic of the tests was confounded by our subsequent discovery of the fact that black-white habits that are learned with one eye are rapidly forgotten by animals prepared with contralateral posterior lesions. Also, we found that binocular re- training, if given to unilateral posterior subjects, yields what appears to be a maximal protection of ultimate retention of the habit (Lee). Hence, at this juncture, we no longer have empirical support for the theory of suppression, and as yet we have not been able to arrive at a satisfying theory to replace it.

The problems still before us are posed by the fact that the habit is cortically dependent, but not because systems related to the cortex are exclusively involved in mediation of the habit when the cerebral cortex is intact. Thus we know that subisocortical systems are formed in preoperative training, and also that the subisocortical systems have components which will serve to interfere, and very strongly, with postoperative learning of reversals of the habit by posterior decorticated subjects (LeVere \& Morlock, 1973). However, those components by themselves will not support postoperative performance of the habit and hence, in von Monakow's (1914) terminology, bilateral posterior extirpations bring about a diaschesis that is so complete that, unless special therapeutic methods are employed, the subject can recover only by developing a new mechanism for postoperative performance of the habit.

However, preoperatively established substrates will continue to mediate performance of the habit provided that the terms of what we shall describe as the rule for postoperative maintenance of access are fulfilled. The terms of the rule are quite explicit. Thus it appears that preoperative substrates remain accessible provided that the subject, after having first sustained a posterior injury, is tested for retention and exhibits some postoperative retention. The generalization is consistent with many observations. These include the fact that overtraining on the habit will not convey protection of retention (Glendenning, 1972; Lashley, 1921a); that postoperative training of an anterior subject will not convey protection of retention following a second-stage posterior ablation (Horel et al., 1966); that one-stage and twostage posterior ablations have the same effects unless the two-stage subjects are given interoperative training (Kircher et al., 1970; Petrinovich \& Carew, 1969; Thompson, 1960); that the foregoing finding remains the same regardless of whether the two-stage subjects are given interoperative treatments with amphetamine (Kircher et al., 1970); that interoperative training will convey protection of retention if practice is given to subjects with incomplete bilateral posterior ablations (Barbas \& Spear, 1976); that monocularly occluded unilateral preparations that exhibit no retention develop compensations which will not protect ultimate retention (Ritchie \& Kirvel); and that the protection of ultimate retention which is seen when unoccluded preparations are retrained appears to be essentially complete (Lee).

When access is lost, it can be reestablished through the use of therapeutic interventions. This is shown 
by the fact that amphetamine treatments selectively facilitate relearning of the habit by bilateral posterior preparations (Braun et al., 1966). The treatments will not work very well for every subject (Jonason et al., 1970), but the outcomes are impressive when they do. Thus a responsive posterior preparation will then perform the habit at about the same level as a bilateral anterior subject and, notably, the anterior deficit is not significantly affected by amphetamine treatments which dramatically affect the behaviors of preoperatively trained posterior preparations (Jonason et al., 1970). Hence, although a treated posterior preparation will not perform the habit at once, its failure to do so can be attributed to functional impairments which are not specifically produced by posterior extirpations.

It must not be supposed that such effects are restricted to corrections of amnesias for the blackwhite discrimination habit. Thus, as we have noted, amphetamine treatments will also reinstate visual placing by cats, which will otherwise exhibit no capacity for placing after having been subjected to radical posterior ablations (Meyer et al., 1963). Moreover, in studies which are not within the scope of this review of our work with visual habits, we have found that the treatments will also permit decorticated rats to perform a shuttlebox avoidance habit provided that the subjects are trained on the habit before the therapy begins (cf. Meyer \& Beattie, 1977). In that situation, the treatments are effective even though decorticated rats will not perform the habit until they have been treated, and even though the treatments are largely ineffective if begun before the animals have first been exposed to the CS-US contingencies of shuttlebox training. Hence, we have found that the treatments will reverse at least three impairments of performance from which, unless the treatments are given to the subjects, there is no recovery at all.

Of course, as we have shown, posterior preparations can relearn the black-white discrimination habit whether they are treated or not. However, unless they are treated with the drug, their amnesias are complete in the sense that they recover by learning a substitutive habit. With respect to amnesias for placing, we have found that cats with posterior ablations will fail to place for months, but then will place again as soon as they are treated with the drug (Meyer et al., 1963). Also, when decorticated rats that have been trained in the shuttlebox avoidance situation are treated with the drug, they almost immediately begin to avoid after having failed to do so in the course of several hundred trials of training (cf. Meyer \& Beattie, 1977). Hence, the disorders which the treatments will correct are enduring impairments of behaviors, and the effects of the treatments have been shown in every instance to be extremely rapid and dramatic.
We believe that these results supply a rationale for the use of pharmacological agents in the treatment of patients with amnestic difficulties. We think, first of all, that we need to revise our notions with respect to the probable causes of amnesias. At present, when patients with amnesias exhibit almost no spontaneous recovery, their problems are usually regarded as arising from losses of associative substrates. However, it is clear from our results that impairments of remembering can be so severe and so persistent as to lead one to think that the problems are memorial when, in fact, they are problems of retrieval. Hence, if we were charged with the rehabilitation of victims of injuries to the brain, we would always begin with the presumption that the patients have recoverable memorial resources.

Although we have studied the effects of amphetamine in reinstating latent habits, we believe that better agents have already been discovered for treatments of the kinds that we envision. Thus, as has been shown by Rigter and his colleagues (Rigter, Janssen-Elbertse, \& Van Riezen, 1977), short-chain peptides and analogs thereof can be used for inducing recoveries from amnesias which are otherwise observed when animals are trained and are then immediately subjected to $\mathrm{CO}_{2}$ and ECS treatments. We think that their results are particularly striking because they have extended our list of examples of impairments of remembering which masquerade as losses of memories, and because they have completed the case against the two-stage theory of memorial encoding (cf. Meyer \& Beattie, 1977).

We would not expect to find that drugs, by themselves, would be of any therapeutic value. Thus, for example, treatments with amphetamine will not convey protection of ultimate retention of the blackwhite habit if given interoperatively to subjects prepared with two-stage ablations of the posterior cortex (Kircher et al., 1969). We think that the drug can activate substrates which otherwise would be completely dormant, but that reestablishment of access depends upon elicitations of behaviors which can then be mediated by the substrates. Hence, we believe that the therapeutic mix would involve a combination of treatments with an agent and behavioral procedures for the evocation of the memories to be reinstated. The latter procedures could be time-consuming, but we doubt that they would be as time-consuming as attempts to prompt an untreated patient or to treat the patient with reeducative methods.

We believe that effective therapies could be devised which would not require continuous treatments with the agents. We base this conclusion upon our observation that treatments with amphetamine, if used to reinstate performance of visual placing, will permit cats with long-chronic cortical ablations to place for days or weeks after one injection of the 
drug (Ritchie, Meyer, \& Meyer, 1976). Also, the animals' performances are best when the automatic consequences of the treatment have subsided. The findings thus suggest that a treatment is required for visual placing to occur, but that maintenance of access is then sustained by other processes.

We would not necessarily expect of an agent that it have a positive effect upon a patient's abilities to learn new materials. Nor would it concern us if the agent failed to have that effect. Thus, again, the goals of the treatments we envision would not be to help the patients to recover by forming new and substitutive habits but, instead, to permit them to make better use of the habits that they already have. In that respect, the treatments would differ in conception from most of the treatments of amnesias which are presently in use, and not excluding treatments which involve the use of drugs or other materials which from time to time have been suggested as agents which will serve to facilitate the processes involved in memory storage.

Although these suggestions are based upon our findings with respect to inductions of recoveries of remembering in only three experimental contexts, we view those inductions as significant because, in terms of classic concepts, our subjects were completely hopeless cases. Our major theoretic conclusion from the findings is simply that the dorsal pallial cortex is not a memory bank. Moreover, and especially inasmuch as we have shown that Lashley's (1935) observations were not a proof of engrammatic storage at the level of the cortex, we know of no observations which deny such a concept. Hence we believe that the logic of the therapeutic methods we propose have been established, and that the clinical assessment of the methods will yield some rich rewards.

\section{REFERENCES}

Ades, H. W., \& RAAB, D. H. Effects of preoccipital and temporal decortication on discrimination in monkeys. Journal of Neurophysiology, 1946, 9, 55-60.

BARBAS, H., \& SPEAR, P. D. Effects of serial unilateral and serial bilateral visual cortex lesions on brightness discrimination relearning in rats. Journal of Comparative and Physiological Psychology, 1976, 90, 279-292.

BAUER, J. H., \& COOPER, R. M. Effects of posterior cortical lesions on performance of a brightness discrimination task: Journal of Comparative and Physiological Psychology, 1964, 58, 84-93.

Berlucci, G., Sprague, J. M., Levy, J., \& DiBerardino, A. C. Pretectum and superior colliculus in visually guided behavior and in flux and form discrimination in the cat. Journal of Comparative and Physiological Psychology Monograph, 1972, 78, 123-172.

Bolles, R. C. Theory of motivation. New York: Harper \& Row, 1970.

Brady, J. V., \& NaUta, W. J. H. Subcortical mechanisms in emotional behavior: Affective changes following septal forebrain lesions in the rat. Journal of Comparative and Physiological Psychology, 1953, 46, 339-346.

BraUn, J. J. The neocortex and visual placing in rats. Brain Research, 1966, 1, 381-394.
BRAUN, J. J. Neocortex and feeding behavior in the rat. Journal of Comparative and Physiological Psychology, 1975, 89, 507-522.

Braun, J. J., MeYer, P. M., \& MeYer, D. R. Sparing of a brightness habit in rats following visual decortication. Journal of Comparative and Physiological Psychology, 1966, 61, 79-82.

Cole, D. D., Sullins, W. R., \& IsaAc, W. Pharmacological modification of the effects of spaced occipital ablations. Psychopharmacologia, 1967, 11, 311-316.

Cooper, R. M., Blochert, K. P., Gillespie, L. A., \& Miller, L. J. Translucent occluders and lesions of posterior neocortex in the rat. Physiology and Behavior, 1972, 8, 693-697.

Dоту, R. W. Survival of pattern vision after removal of striate cortex in the cat. Journal of Comparative Neurology, 1971, 143, 341-369.

DRU, D., Walker, J. P., \& WAlker, J. B. Self-produced locomotion restores visual capacity after striate lesions. Science, 1975, 187, 265-266.

Fischman, M. W., \& MeIKIE, T. H., JR. Visual intensity discrimination in cats after serial tectal and cortical lesions. Journal of Comparative and Physiological Psychology, 1965, 59, 193-201.

Gellerman, L. W. Chance orders of alternating stimuli in visual discrimination experiments. Journal of Genetic Psychology, 1933, 42, 207-208.

GLENDENNING, R. L. Effects of training between two unilateral lesions of visual cortex upon ultimate retention of black-white habits by rats. Journal of Comparative and Physiological Psychology, 1972, 80, 216-229.

Goodman, D. C., \& Horel, J. A. Sprouting of optic tract projections in the brain stem of the rat. Journal of Comparative Neurology, 1966, 127, 71-88.

HoREL, J. A. Effects of subcortical lesions on brightness discrimination acquired by rats without visual cortex. Journal of Comparative and Physiological Psychology, 1968, 65, 103-109.

Horel, J. A., Bettinger, L. A., Royce, G. J., \& MeYer, D. R. Role of neo-cortex in the learning and relearning of two visual habits by the rat. Journal of Comparative and Physiological Psychology, 1966, 61, 66-78.

HugHEs, H. C. Anatomical and neurobehavioral investigations concerning the thalamocortical organization of the rat's visual system. Doctoral dissertation, The Ohio State University, 1976.

Jonason, K. R., Lauber, S. M., Robbins, M. J., Meyer, P. M., \& MEYER, D. R. Effects of amphetamine upon relearning pattern and black-white discriminations following neocortical lesions in rats. Journal of Comparative and Physiological Psychology, 1970, 73, 47-55.

Kircher, K. A., Braun, J. J., Meyer, D. R., \& Meyer, P. M. Equivalence of simultaneous and successive neocortical ablations in production of impairments of retention of black-white habits in rats. Journal of Comparative and Physiological Psychology, $1970,71,420-425$.

KIRVEL, R. D. Sensorimotor responsiveness in rats with unilateral superior collicular and amygdaloid lesions. Journal of Comparative and Physiological Psychology, 1975, 89, 882-891.

KiRVEL, R. D., GREenfield, R. A., \& MeYer, D. R. Multimodal sensory neglect in rats with radical unilateral posterior ablations. Journal of Comparative and Physiological Psychology, 1974, 87, 156-162.

KLEINER, F. B., MEYer, P. M., \& MeYer, D. R. Effects of simultaneous septal and amygdaloid lesions upon emotionality and retention of a black-white discrimination. Brain Research, 1967, $5,359-468$.

Kolb, B., \& Nonneman, A. J. Functional development of prefrontal cortex in rats continues into adolescence. Science, 1976, 193, 335-336.

KRIEG, W. J. S. Connections of the cerebral cortex. I. The albino rat. A. Topography of the cortical areas. Journal of Comparative Neurology, 1946, 84, 221-275.

LASHLEY, K. S. Studies of cerebral function in learning. II. The effects of long-continued practice upon cerebral localization. Journal of Comparative Psychology, 1921, 1, 453-468. (a)

LASHLEY, K. S. Studies of cerebral function in learning. III. The motor areas. Brain, 1921, 44, 255-286. (b) 
LASHLEY, K. S. The mechanism of vision: XII. Nervous structures concerned in habits based on reactions to light. Comparative Psychology Monographs, 1935, 11, 43-79.

LASHLEY, K. S. The functioning of small remnants of the visual cortex. Journal of Comparative Neurology, 1939, 70, 45-67.

LEVERE, T. E. Neural stability, sparing, and behavioral recovery following brain damage. Psychological Review, 1975, 82, 344-358.

LEVERE, T. E., \& Morlock, G. W. Nature of visual recovery following posterior neodecortication in the hooded rat. Journal of Comparative and Physiological Psychology, 1973, 83, 62-67.

Melton, A. W. The end-spurt in memorization curves as an artifact of the averaging of individual curves. Psychological Monographs, 1936, 47, 119-134.

MEYER, D. R. Access to engrams. American Psychologist, 1972. 27. 124-133.

MEYeR, D. R., \& BeATtie, M. S. Some properties of substrates of memory. In L. Miller, C. Sandman, \& A. Kastin (Eds.), Neuropeptide influences on brain and behavior. New York: Raven Press, 1977.

Me Yer, D. R., Cho, C., \& Wesemann, A. F. On problems of conditioning discriminated lever-press avoidance responses. Psychological Review, 1960, 67, 224-228.

Meyer, P. M., Dalby, D. A., Glendenning, K. A., Lauber, S. M., \& MEYER, D. R. Behavior of cats with lesions of the septal forebrain or anterior sigmoid neocortex. Journal of Comparative and Physiological Psychology, 1973, 85, 491-501.

Meyer, P. M., Horel, J. A., \& MeYer, D. R. Effects of $\mathrm{dl}$-amphetamine upon placing responses in neodecorticate cats. Journal of Comparative and Physiological Psychology, 1963, 56. 402-404.

MEYER, D. R., Is AAC, W., \& MAHER, B. The role of stimulation in spontaneous reorganization of visual habits. Journal of Comparative and Physiological Psychology, 1958, 51, 546-548.

MEYER. P. M., \& MEYER, D. R. Neurosurgical procedures with special reference to aspiration lesions. In R. B. Myers (Ed.), Methods in neuro-biology. New York: Academic Press, 1971.

Meyer, D. R., Treichler, F. R., \& MeYer, P. M. Discrete-trial training techniques and stimulus variables. In A. M. Schrier, H. F. Harlow, \& F. Stollnitz (Eds.), Behavior of nonhuman primates. New York: Academic Press, 1965.

Meyer, P. M., Yutzey, D. A., Dalby, D. A., \& MeYer, D. R. Effects of simultaneous septal-visual, septal-anterior and anterior-posterior lesions upon relearning a black-white discrimination. Brain Research, 1968, 8, 281-290.

Monakow, C. von. Die Lokalisation im Grosshirm und der Abbau der Function durch kortikale Herde. Wiesbaden: Bergmann, 1914.

Norton, A. C., \& CLARK, G. Effects of cortical and collicular lesions on brightness and flicker discrimination in the cat. Vision Research, 1963, 3, 29-44.

PAsIK, P., \& PAsik, T. Extrageniculate vision in the monkey. V. Role of accessory optic system. Journal of Neurophysiology, 1973, 36, 450-457.

Pavlov, I. P. Conditioned reflexes. London: Oxford University Press, 1927.

Petrinovich, L., \& Bliss, D. Retention of a learned brightness discrimination following ablations of the occipital cortex in the rat. Journal of Comparative and Physiological Psychology, 1966, 61, 136-138.

Petrinovich, L., \& Carew, T. J. Interaction of neocortical lesion size and interoperative experience in retention of a learned brightness discrimination. Journal of Comparative and Physiological Psychology, 1969, 68, 451-454.

RAAB, D. H., \& ADES, H. W. Cortical and midbrain mediation of a conditioned discrimination of acoustic intensities. American Journal of Psychology, 1946, 59, 59-83.

Rigter, H., Janssen-Elbertse, R., \& van Riezen, H. Reversal of amnesia by an orally active ACTH analog (Org 2766). In L.
Miller, C. Sandman, \& A. Kastin (Eds.), Neuropeptide influences on brain and behavior. New York: Raven Press, 1977.

Ritchie, G. D., Meyer, P. M., \& MeYer, D. R. Residual spatial vision of cats with lesions of the visual cortex. Experimental Neurology, 1976, 53, 227-254.

SChefF, S. W., \& WRIGHT, D. C. Behavioral and electrophysiological evidence for cortical reorganization of function in rats with serial lesions of the visual cortex. Physiological Psychology, 1977, 5, 103-107.

Scheff, S. W., Wright, D. C., Morgan, W. K., \& Bowers, R. P. The differential effects of additional cortical lesions in rats with single or multiple stage lesions of the visual cortex. Physiological Psychology, 1977, 5, 97-102.

Schuck, J. R., \& Coppola, L. A. Contact occluders for restricting vision in the rat. American Journal of Psychology, 1963, 76. 135-137.

Sheridan, C. L., \& Shrout, L. L. Interocular transfer in the rat: The role of the occlusion process. Psychonomic Science, 1965. 2, 173-174.

S mith, K. U. Visual discrimination in the cat: The relation between pattern vision acuity and the optic projection centers of the nervous system. Journal of Genetic Psychology, 1938, 53, 251-272.

SPEAR, P. D., \& Barbas, H. Recovery of pattern discrimination ability in rats receiving serial or one-stage visual cortex lesions. Brain Research, 1975, 94, 337-346.

SPEAR, P. D., \& BraUn, J. J. Nonequivalence of normal and posteriorly neo-decorticated rats on two brightness discrimination problems. Journal of Comparative and Physiological Psychology, 1969, 67, 235-239.

SPRAGUE, J. M. Interaction of cortex and superior colliculus in mediation of visually guided behavior in the cat. Science, 1966, 153, 1544-1547.

Sprague, J. M., Levy, J., DiBerardino, A., \& Berlucchi, G. Visual cortical areas mediating form discrimination in the cat. Journal of Comparative Neurology, in press.

Sprague, J. M., \& Meikle, T. H., JR. The role of the superior colliculus in visually guided behavior. Experimental Neurology, $1965,11,115-146$.

Stew ART, J. W., \& Ades, H. W. The time factor in reintegration of a learned habit lost after temporal lobe lesions in the monkey (Macaca mulatta). Journal of Comparative and Physiological Psychology, 1951, 44, 479-486.

Thompson, R. Retention of a brightness discrimination following neo-cortical damage in the rat. Journal of Comparative and Physiological Psychology, 1960, 53, 212-215.

Thompson, R., \& BRYANT, J. H. Memory as affected by activity of the relevant receptor. Psychological Reports, 1955, 1, 393-400.

Thompson, R. F., Johnson, R. H., \& Hoopes, J. J. Organization of auditory, somatic sensory, and visual projection to association fields of cerebral cortex in the cat. Journal of Neurophysiology. 1963, 26, 343-364.

Urbaitis, J. C., \& Meikle, T. H., JR. Relearning of a dark-light discrimination by cats after cortical and collicular lesions. Experimental Neurology, 1968, 20, 295-311.

WooD, B. S. Monocular relearning of a dark-light discrimination by cats after unilateral cortical and collicular lesions. Brain Research, 1975, 83, 156-162.

Woolsey, C. N., Settlage, P. H., Meyer, D. R., Sencer, W.. Pinto-Hamuy, T., \& Travis, A. M. Patterns of localization in precentral and "supplementary" motor areas and their relation to the concept of a premotor area. In Patterns of organization in the central nervous system. Baltimore: Williams \& Wilkins, 1950. Pp. 238-264.

(Received for publication September 22, 1976; revision accepted March 25, 1977.) 